\title{
Targeting murine heart and brain: visualisation conditions for multi-pinhole SPECT with ${ }^{99 m}$ Tc- and ${ }^{123}$ I-labelled probes
}

\author{
M. Pissarek • J. Meyer-Kirchrath • T. Hohlfeld • \\ S. Vollmar • A. M. Oros-Peusquens • U. Flögel • \\ C. Jacoby $\cdot$ U. Krügel $\cdot$ N. Schramm
}

Received: 20 September 2008 / Accepted: 2 April 2009/Published online: 7 May 2009

(C) The Author(s) 2009. This article is published with open access at Springerlink.com

\begin{abstract}
Purpose The study serves to optimise conditions for multipinhole SPECT small animal imaging of ${ }^{123} \mathrm{I}-$ and ${ }^{99 \mathrm{~m}} \mathrm{Tc}-$ labelled radiopharmaceuticals with different distributions in murine heart and brain and to investigate detection and dose range thresholds for verification of differences in tracer uptake.

Methods A Triad 88/Trionix system with three 6-pinhole collimators was used for investigation of dose requirements for imaging of the dopamine $\mathrm{D}_{2}$ receptor ligand $\left[{ }^{123} \mathrm{I}\right] \mathrm{IBZM}$ and the cerebral perfusion tracer $\left[{ }^{99 \mathrm{~m}} \mathrm{Tc}\right] \mathrm{HMPAO}(1.2-$ $0.4 \mathrm{MBq} / \mathrm{g}$ body weight) in healthy mice. The fatty acid $\left[{ }^{123} \mathrm{I}\right] \mathrm{IPPA}(0.94 \pm 0.05 \mathrm{MBq} / \mathrm{g}$ body weight $)$ and the perfusion tracer $\left[{ }^{99 \mathrm{~m}} \mathrm{Tc}\right]$ sestamibi $(3.8 \pm 0.45 \mathrm{MBq} / \mathrm{g}$ body weight) were applied to cardiomyopathic mice overexpressing the prostaglandin $\mathrm{EP}_{3}$ receptor.

Results In vivo imaging and in vitro data revealed $45 \mathrm{kBq}$ total cerebral uptake and $201 \mathrm{kBq}$ cardiac uptake as thresholds
\end{abstract}

Electronic supplementary material The online version of this article (doi:10.1007/s00259-009-1142-9) contains supplementary material, which is available to authorized users.

\section{Pissarek ( $\square)$}

Institute of Neurosciences and Biophysics-Nuclear Chemistry

(INB-4), Research Centre Juelich,

Leo-Brandt-Str.,

52428 Juelich, Germany

e-mail: m.pissarek@fz-juelich.de

A. M. Oros-Peusquens

Institute of Neurosciences and Biophysics-Medicine (INB-3),

Research Centre Juelich,

Juelich, Germany

N. Schramm

Central Institute for Electronics, Research Centre Juelich,

Juelich, Germany for visualisation of striatal $\left[{ }^{123} \mathrm{I}\right] \mathrm{IBZM}$ and of cardiac $\left[{ }^{99 \mathrm{~m}} \mathrm{Tc}\right]$ sestamibi using 100 and $150 \mathrm{~s}$ acquisition time, respectively. Alterations of maximal cerebral uptake of $\left[{ }^{123} \mathrm{I}\right] \mathrm{IBZM}$ by $>20 \%$ (116 kBq) were verified with the prerequisite of $50 \%$ striatal of total uptake. The labelling with $\left[{ }^{99 \mathrm{~m}} \mathrm{Tc}\right]$ sestamibi revealed a 30\% lower uptake in cardiomyopathic hearts compared to wild types. $\left[{ }^{123} \mathrm{I}\right] \mathrm{IPPA}$ uptake could be visualised at activity doses of $0.8 \mathrm{MBq} / \mathrm{g}$ body weight.

Conclusion Multi-pinhole SPECT enables detection of alterations of the cerebral uptake of ${ }^{123} \mathrm{I}$ - and ${ }^{99 \mathrm{~m}} \mathrm{Tc}$-labelled tracers in an appropriate dose range in murine models targeting physiological processes in brain and heart. The thresholds of detection for differences in the tracer uptake determined under the conditions of our experiments well reflect distinctions in molar activity and uptake characteristics of the tracers.

Keywords Brain $\cdot$ Heart $\cdot\left[{ }^{123} \mathrm{I}\right] \mathrm{IBZM} \cdot$ Mice . Multi-pinhole SPECT $\cdot\left[{ }^{99 \mathrm{~m}} \mathrm{Tc}\right]$ sestamibi

\section{J. Meyer-Kirchrath • T. Hohlfeld}

Institute of Pharmacology and Clinical Pharmacology,

Heinrich Heine University,

Düsseldorf, Germany

U. Flögel · C. Jacoby

Institute of Heart and Circulation Physiology,

Heinrich Heine University,

Düsseldorf, Germany

S. Vollmar

Max Planck Institute for Neurological Research,

Cologne, Germany

U. Krügel

Rudolf Boehm Institute of Pharmacology and Toxicology,

University of Leipzig,

Leipzig, Germany 


\section{Introduction}

During the last decade multi-pinhole SPECT systems of various designs have been proposed for use in preclinical research and also for some clinical applications [1-9].

Multi-pinhole designs for SPECT applications range from systems with a few detectors using collimators with a large number of pinholes, which do not reduce the counting rate substantially and allow for high time resolution, to systems with several detectors using collimators with only a few pinholes, or alternatively, annular detectors, with emphasis on improvement of the spatial resolution. Clinical applications of such systems have been proposed for the assessment of alterations due to hyperplastic parathyroid glands [7, 10] and for diagnosis of rheumatism, arthrosis [5] and coronary heart disease [8].

In preclinical research, multi-pinhole SPECT is developing into a complement to PET as a tool for in vivo imaging of pharmacodynamics and pharmacokinetics of receptor ligands [11], tracers of metabolic processes [12, 13] and physiological properties in healthy and diseased small animals [3, 14-17]. Dedicated SPECT and PET systems can provide sufficient spatial and temporal resolution for quantitative observation of such processes even in mouse models.

The high availability of SPECT radiopharmaceuticals, increasing experience with SPECT tracers in small animal imaging [3, 4, 13, 18-22] and improvement of resolution parameters of SPECT with multi-pinhole devices contribute to broadening the role that multi-pinhole SPECT (MPS) is able to play in small animal imaging. The use of a broad range of tracers is especially important for the study of transgenic mouse models, which have become an essential tool of biological research during the last two decades.

Due to the high variety of gamma cameras applied to small animal imaging, reproducibility of experiments requires a detailed description of the visualisation conditions used for different tracers, requirements of tracer dose and technical parameters of the SPECT devices, sensitivity as well as geometric properties of the animal model investigated [4, 23, 24].

The present study focuses on the evaluation of the parameters required for the imaging of mouse brains and hearts using different tracers and animal models and a MPS including three 6-pinhole collimators. To this aim, the definition of the dose range for different tracers and the quantitative assessment of detection borders of anatomical and molecular alterations were performed in physiological and pathophysiological mouse models by means of the MPS. We investigated the biodistribution of the dopamine $\mathrm{D}_{2}$ receptor ligand $\left[{ }^{123} \mathrm{I}\right] \mathrm{IBZM}$ and the flow tracer $\left[{ }^{99 \mathrm{~m}} \mathrm{Tc}\right]$ HMPAO in the brains of normal NMRI mice. The tracers are both widely used in experimental and clinical applica- tions for the evaluation of dopaminergic signal transduction [25-28] and cerebral perfusion. Another set of tracers, the long chain fatty acid [ $\left.{ }^{123} \mathrm{I}\right] \mathrm{IPPA}$ and the flow tracer $\left[{ }^{99 \mathrm{~m}} \mathrm{Tc}\right]$ sestamibi, were applied to $\mathrm{B} 6 \mathrm{C} 3 \mathrm{~F} 1-\mathrm{Tg}(\mathrm{EP} 3)$ mice with overexpression of the prostaglandin $\mathrm{EP}_{3}$ receptor and to wild-type littermates [29]. Although the prostaglandin $\mathrm{EP}_{3}$ receptor is known to mediate cardiac protection during ischaemia and reperfusion, the development of cardiac hypertrophy has been observed in these animals. The recent investigations contribute to the further characterisation of the physiological and metabolic phenotype of these hearts on the one hand as well as to the estimation of the borders of detection of alterations in the uptake of radiopharmaceuticals in normal tissues and under pathophysiological conditions on the other hand. Two data processing tools are compared for their abilities in assessment of the SPECT imaging data. Localisation of anatomical structures and assessment of alterations in their size is supported by MR imaging of brain and heart.

\section{Materials and methods}

\section{Chemicals}

Ketamine and xylazine were purchased from SigmaAldrich (Deisenhofen, Germany), $\left[{ }^{123} \mathrm{I}\right] \mathrm{IBZM}$ (iolopride; $\left[{ }^{123} \mathrm{I}\right](S)$-2-hydroxy-3-iodo-6-methoxy- $N$-[(1-ethyl-2-pyrrolidinyl-9-methyl)]-benzamide; specific activity: $>74 \mathrm{TBq} /$ mmol) and [ $\left.{ }^{99 \mathrm{~m}} \mathrm{Tc}\right] \mathrm{HMPAO}\left(\left[{ }^{99 \mathrm{~m}} \mathrm{Tc}\right]-(\mathrm{D}, \mathrm{L})\right.$-hexa-methylpropylene-amine oxime; Ceretec preparation kit) from Amersham Buchler (Braunschweig, Germany), [ $\left.{ }^{99 \mathrm{~m}} \mathrm{Tc}\right]-2-$ methoxy-iodobutyl-isonitrile (Cardiolite) preparation kit was supplied by Bristol-Myers Squibb and $\left[{ }^{123}\right.$ I]IPPA (para-iodo-phenyl-pentadecanoic acid; specific activity: 185-460 GBq/mmol) has been synthesised by Dr. Peter van Doremalen (Eindhoven, The Netherlands).

For the SPECT measurements a Triad 88 system upgraded with 6-pinhole collimators with an average sensitivity of $835 \mathrm{cps} / \mathrm{MBq}$ and an inner diameter of $1.5 \mathrm{~mm}$ was used as described previously [2, 30].

\section{Animals}

All animals were obtained from Charles River Deutschland GmbH (Sulzfeld, Germany) (NMRI mice) or the Animal Care Unit of the Heinrich Heine University Düsseldorf [B6C3F1-Tg(EP3)].

Mice with cardiac-specific overexpression of the porcine homologue of the human $\mathrm{G}_{\mathrm{i}} / \mathrm{G}_{\mathrm{q}}$-coupled $\mathrm{EP}_{3 \mathrm{II}}$ receptor subtype under control of the $\alpha$-myosin heavy chain $(\alpha-$ MHC) promoter were generated using standard techniques as described previously [29]. 
The animals were kept at 12/12-h dark-light cycles. All procedures were performed in accordance with the German Guidelines for Care and Use of Laboratory Animals and approved by the governmental Animal Research Committee.

General experimental procedure

The investigations were performed in 24 animals (7 NMRI: 34-50 g body weight; 17 B6C3F1(EP3), 7 transgenic, 10 wild-type; $18-30 \mathrm{~g}$ ). For the SPECT experiments and for brain MRI the mice were anaesthetised using ketamine/ xylazine (i.p. application of $100 \mathrm{mg} / 10 \mathrm{mg}$ per $100 \mathrm{~g}$ body weight and hour). Anaesthesia was started $15 \mathrm{~min}$ before injection of the radiopharmaceuticals. For the SPECT investigations a plastic v-notch was placed in the mouth approximately $5 \mathrm{~min}$ after start of anaesthesia to ensure that obstruction of the upper respiratory tract was avoided.

All radiopharmaceuticals were injected via the tail vein. For the brain SPECT the mice were placed in prone position and for the cardiac SPECT in supine position in an animal bed in the centre of the multi-pinhole SPECT system. At the end of the observation period the brains and 11 of the hearts were excised and the activity was measured immediately by means of an Activimeter Isomed 1000 (Version 2.30, Nuklear-Medizintechnik Dresden GmbH, Dresden, Germany). Subsequently, the excised organs were scanned ex vivo (four brains and four $\left[{ }^{99 \mathrm{~m}} \mathrm{Tc}\right]$-sestamibi labelled hearts) by means of the MPS camera system with the same acquisition time as used for the last in vivo measurement.

The anaesthesia during MRI of the brain was the same as for the SPECT investigations. For cardiac MRI the animals were anaesthetised with $1.5 \%$ isoflurane in a gas mixture of $30 \%$ oxygen in nitrogen.

\section{Brain SPECT}

Cerebral uptake of $\left[{ }^{123} \mathrm{I}\right] \mathrm{IBZM}$ and $\left[{ }^{99 \mathrm{~m}} \mathrm{Tc}\right] \mathrm{HMPAO}$ was investigated in six NMRI mice. Four animals were given i.v. doses of $0.44,0.56,0.61$ and $0.95 \mathrm{MBq}\left[{ }^{123} \mathrm{I}\right] \mathrm{IBZM} / \mathrm{g}$ body weight and two other mice 0.47 and $1.16 \mathrm{MBq}$ $\left[{ }^{99 \mathrm{~m}} \mathrm{Tc}\right] \mathrm{HMPAO} / \mathrm{g}$ body weight. Measurements of $\left[{ }^{123} \mathrm{I}\right]$ IBZM uptake started $15 \mathrm{~min}$ after tracer injection and continued during eight acquisition periods. Acquisition time was $100 \mathrm{~s}$ using 10 steps of rotation. After the end of the last acquisition period the brains were dissected from the skulls and the activity determined using the activimeter. The excised brains were imaged with SPECT using the same acquisition time as used for in vivo measurements.

MPS measurement of $\left[{ }^{99 \mathrm{~m}} \mathrm{Tc}\right] \mathrm{HMPAO}$ was performed using $140 \mathrm{~s}$ acquisition time and 10 steps of rotation starting 75 min post-injection (p.i.).

\section{Heart SPECT}

Cardiac uptake of $\left[{ }^{99 \mathrm{~m}} \mathrm{Tc}\right]$ sestamibi or $\left[{ }^{123} \mathrm{I}\right] \mathrm{IPPA}$ was investigated in 15 male $(n=3) /$ female $(n=12)$ mice (transgenic: 6, wild-type: 9). For measurement of $\left[{ }^{99 \mathrm{~m}} \mathrm{Tc}\right.$ ] sestamibi the tracer was injected in doses of $3.8 \pm$ $0.39 \mathrm{MBq} / \mathrm{g}$ body weight. The imaging of $\left[{ }^{99 \mathrm{~m}} \mathrm{Tc}\right]$ sestamibi was performed using $150 \mathrm{~s}$ acquisition time starting $15 \mathrm{~min}$ p.i. $\left[{ }^{123} \mathrm{I}\right] \mathrm{IPPA}$ uptake was observed after application of $0.94 \pm 0.05 \mathrm{MBq} / \mathrm{g}$ body weight with $100 \mathrm{~s}$ acquisition time and 10 steps of rotation without gating starting $3 \mathrm{~min}$ p.i.

\section{Reconstruction and quantification}

The reconstruction of the images was performed using HISPECT multi-pinhole reconstruction software (Scivis GmbH , Göttingen, Germany). Quantification of the activity accumulated in volumes of interest and regions of interest (ROI), respectively, was performed with Vinci 2.3.1. [31] and InVivoScope processing tools (courtesy of Dr. Christian Lackas) as described previously [32]. Standard uptake values (SUV) were calculated according to the equation: $\mathrm{SUV}=$ activity per $\mathrm{g}$ target tissue/activity applied per animal $*$ g body weight $[33,34]$. The segmental evaluation of the cardiac distribution of $\left[{ }^{99 \mathrm{~m}} \mathrm{Tc}\right]$ sestamibi was performed choosing the ROIs as described previously [35]. The quantification of cardiac uptake using the InVivoScope processing tool was performed by determination of the sum of intensity signals within the whole heart. In contrast, the calculation of the intensity by means of the Vinci processing tool was performed by determination of the intensities measured in the wall of the left ventricle in short axis view, horizontal long axis view and vertical long axis view and evaluation of the total intensity in the apparent volume of the left ventricle using these data.

MR imaging of brain and heart

MR brain imaging was performed using a $9.4 \mathrm{~T}$ animal scanner based on a horizontal superconducting magnet (Magnex, Scientific Ltd., Yarnton, UK) with a bore size of $16 \mathrm{~cm}$ equipped with a $10-\mathrm{cm}$ inner diameter gradient coil and a gradient strength of $270 \mathrm{mT} / \mathrm{m}$ [30]. A 20-mm surface coil was used for both excitation and signal detection.

Cardiac MR imaging was performed using a vertical Bruker DRX 9.4 T NMR spectrometer, with a 40-mm gradient set (maximum strength $1 \mathrm{~T} / \mathrm{m}$ ) and a $30-\mathrm{mm}$ birdcage resonator. The images were acquired using an ECG- and respiration-gated gradient echo cine sequence (repetition time of $5 \mathrm{~ms}$, echo time $2.5 \mathrm{~ms}$, flip angle $15^{\circ}$, field of view $30 \times 30 \mathrm{~mm}^{2}$, reconstruction matrix site $256 \times$ 256, slice thickness $=1 \mathrm{~mm}$ ). 


\section{Statistical analysis}

Results are expressed as mean \pm standard error of mean (SEM). Significance of differences between several groups were identified using one-way analysis of variance (ANOVA) followed by the Student-Newman-Keuls test for multiple comparison. Comparison between two groups was performed using a paired and an unpaired Student's $t$ test. Pearson's coefficient was used to test the significance of correlations between the data obtained. A probability value less than 0.05 was considered significant.

\section{Results}

$\left[{ }^{123} \mathrm{I}\right] \mathrm{IBZM}$ measurements in vivo, ex vivo and in vitro

The MPS measurements of the distribution of $\left[{ }^{123} \mathrm{I}\right] \mathrm{IBZM}$ revealed a good discrimination of the different activities in vivo. Moreover, the in vivo data showed a good correlation with in vitro measurements.

Uptake of $\left[{ }^{123} \mathrm{I}\right] \mathrm{IBZM}$ was observed for $3 \mathrm{~h}$. Figure 1 presents transversal slices of the brain after application of $0.61 \mathrm{MBq} / \mathrm{g}\left[{ }^{123} \mathrm{I}\right] \mathrm{IBZM}$ (34 $\mathrm{g}$ body weight) in relation to transversal MR images (36 g body weight). Figure 2 shows transversal and sagittal slices of the brains at the four dose levels during the fifth acquisition period.

The evaluation of uptake of $\left[{ }^{123} \mathrm{I}\right] \mathrm{IBZM}$ by means of the Vinci 2.3.1. processing tool shown in Fig. 3a was performed using a volume-based approach as described earlier [30]. Figure $3 \mathrm{~b}$ presents the respective data obtained by means of the InVivoScope processing tool. The proportion between specific and non-specific binding related to the total volume of the brain decreased from 1:5 to values $>1$ at the 100 th min of the observation period (fifth acquisition period; data not shown). A comparison of the data points obtained for the four doses (for each dose mean value of all acquisition periods with exception of period 2 and 6) using ANOVA followed by the StudentNewman-Keuls post hoc test (Fig. 4a, b) reveals the range in which the multi-pinhole system reflects differences in the uptake of the receptor ligand under the experimental condition described. Differences between the mean values obtained using the Vinci 2.3.1. processing tool were identified as significant upward from $20 \%$ of the uptake at the maximal dose activities applied. The same uptake was reflected with a $30 \%$ difference $(610 \mathrm{kBq} / \mathrm{g}$ body weight and $510 \mathrm{kBq} / \mathrm{g}$ body weight obtaining group) but with the same probability of significance with the InVivoScope processing tool. Figure 5 shows good correlations between activity measurements of excised brains in vitro and the intensity values observed in vivo (Fig. 5a) analysed by means of the InVivoScope data processing tool. The border of detection is indicated by interpolation of the regression line to the $\mathrm{x}$-axis (Fig. 5a) revealing $45 \mathrm{kBq}$ as the smallest activity accumulated in the whole brain under in vivo conditions for appropriate visualisation of the striata following application of $\left[{ }^{123} \mathrm{I}\right] \mathrm{IBZM}$. The SUV calculated for all brains was $\mathrm{SUV}=0.36 \pm 0.016$ giving a relative standard deviation of $9 \%$ for the $\left[{ }^{123}\right.$ I]IBZM experiments reflecting a variation coefficient in a range expectable for an in vivo method for the determination of physiological parameters applied to a small group of animals. InVivoScope data obtained in the striata in vivo and their correlation with the respective data points determined by means of the Vinci processing tool are shown for the third
Fig. 1 MR and $\left[{ }^{123} \mathrm{I}\right] \mathrm{IBZM}$ SPECT images of murine brains. a Transversal MR images were obtained with an echo time of TE $14 \mathrm{~ms}$ and a repetition time of TR 2,000 ms. Measurement was performed using a field of view of $32 \times 19.2 \mathrm{~mm}$ and a matrix of $512 \times 256$. Slices of $0.7 \mathrm{~mm}$ thickness were scanned with 0.7-mm gaps between the registered planes. b Transversal multipinhole SPECT images of a brain obtained following processing by means of Vinci 2.3.1; $0.61 \mathrm{MBq}$ $\left[{ }^{123} \mathrm{I}\right] \mathrm{IBZM} / \mathrm{g}$ body weight were applied. SPECT measurement was performed using acquisition times of $100 \mathrm{~s}$ and 10 steps of rotation. 1 position of the harderian glands, 2 position of the striata
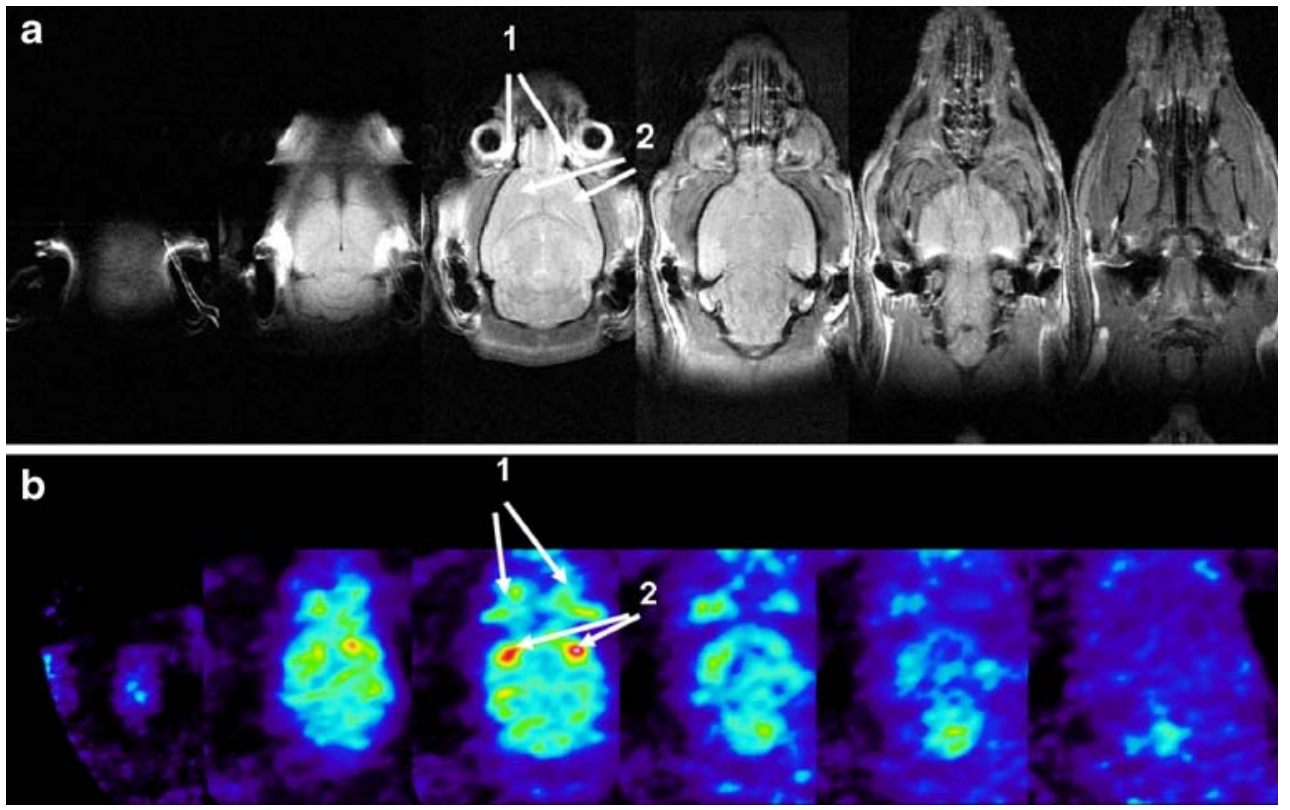
Fig. 2 Transversal and sagittal slices of murine brains with different uptake of $\left[{ }^{123} \mathrm{I}\right] \mathrm{IBZM}$. Brains of four mice are shown following application of $0.95(a)$, $0.61(b), 0.56(c)$ and $0.44(d)$ $\mathrm{MBq} / \mathrm{g}$ during the fifth acquisition period (A transversal slices, B sagittal slices). MPS was performed using acquisition times of $100 \mathrm{~s}$ per scan, 10 steps of rotation and a radius of rotation of $37 \mathrm{~mm}$. Body weights of the mice were $42 \mathrm{~g}(a), 34 \mathrm{~g}(b)$, $34 \mathrm{~g}(c)$ and $50 \mathrm{~g}(d)$. Maximum intensity projections of $a$ have been shown in [30]

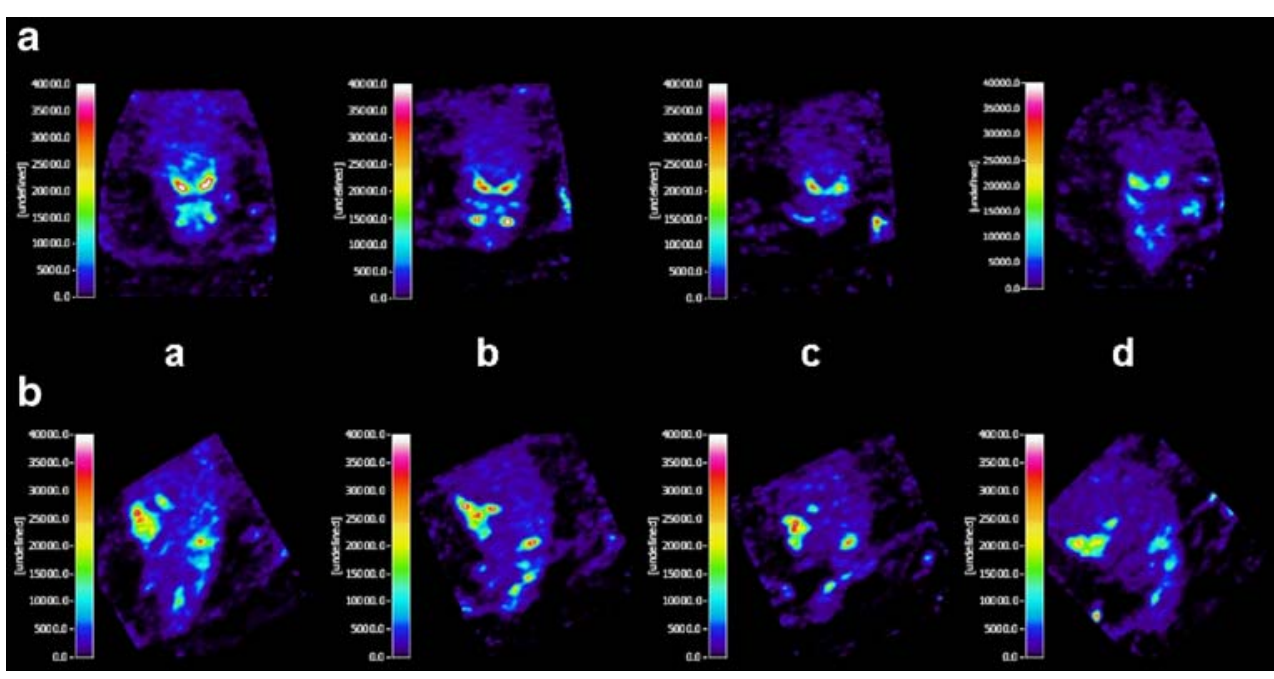

acquisition period (Fig. 5b) and for the eighth acquisition period (Fig. 5c).

The activities applied in the present experiments were in accordance with the range proposed by the modified
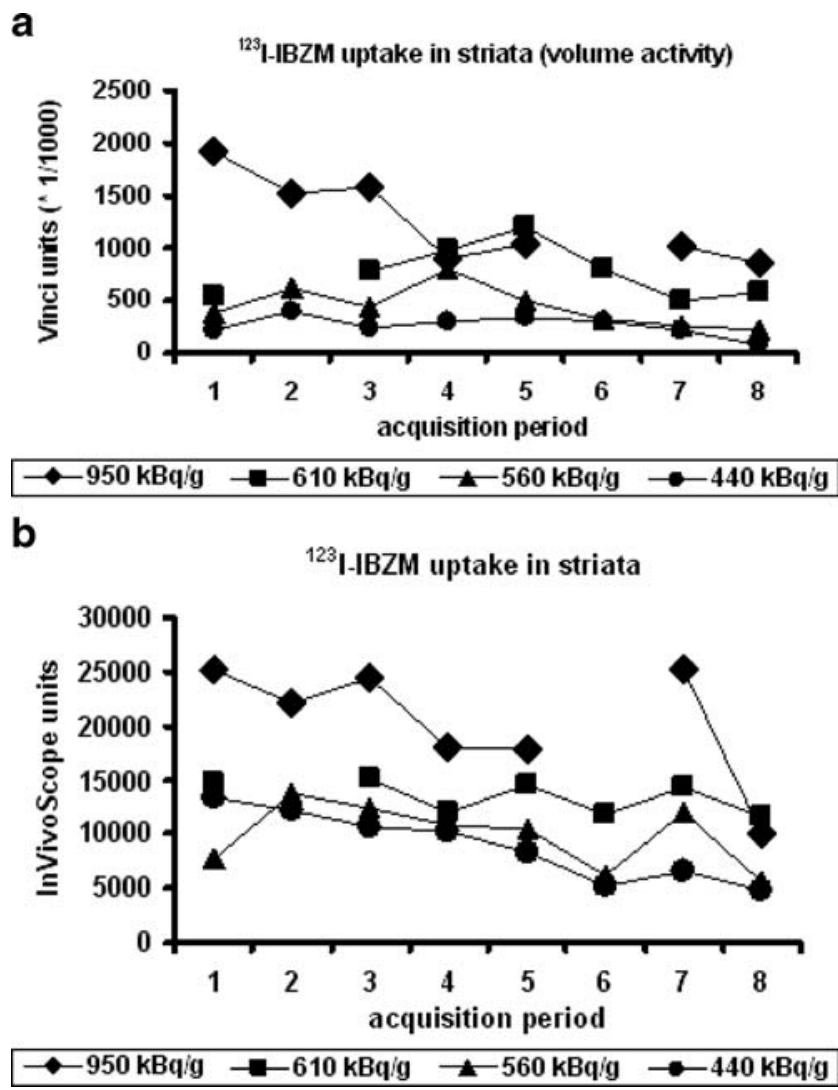

Fig. 3 Time course of striatal uptake of $\left[{ }^{123} \mathrm{I}\right] \mathrm{IBZM}$. Uptake of $\left[{ }^{123} \mathrm{I}\right]$ IBZM is shown after application of $0.44,0.56,0.61$ and $0.95 \mathrm{MBq} / \mathrm{g}$ body weight in mice. Imaging conditions were used as described in the legend of Fig. 2. The numbers of the $\mathrm{x}$-axis correspond to the consecutive acquisition periods 1 to 8 . a Time course analysed using the Vinci 2.3.1. processing tool. b Time course analysed using the InVivoScope processing tool
Goertzen equation [4, 30]. Moreover, Eq. 1 allows a simple estimation of the activity necessary for equivalent visualisation of $\left[{ }^{123} \mathrm{I}\right] \mathrm{IBZM}$ binding (or ligands with similar cerebral uptake behaviour) to striata in different species with different brain and body weights.

$A 2=\frac{D 1 * B R w t 1 * B D w t 2}{B R w t 2}$

A2 activity to apply to the animal of the second species

D1 tissue uptake in species 1 corresponding to the desired visualisation level
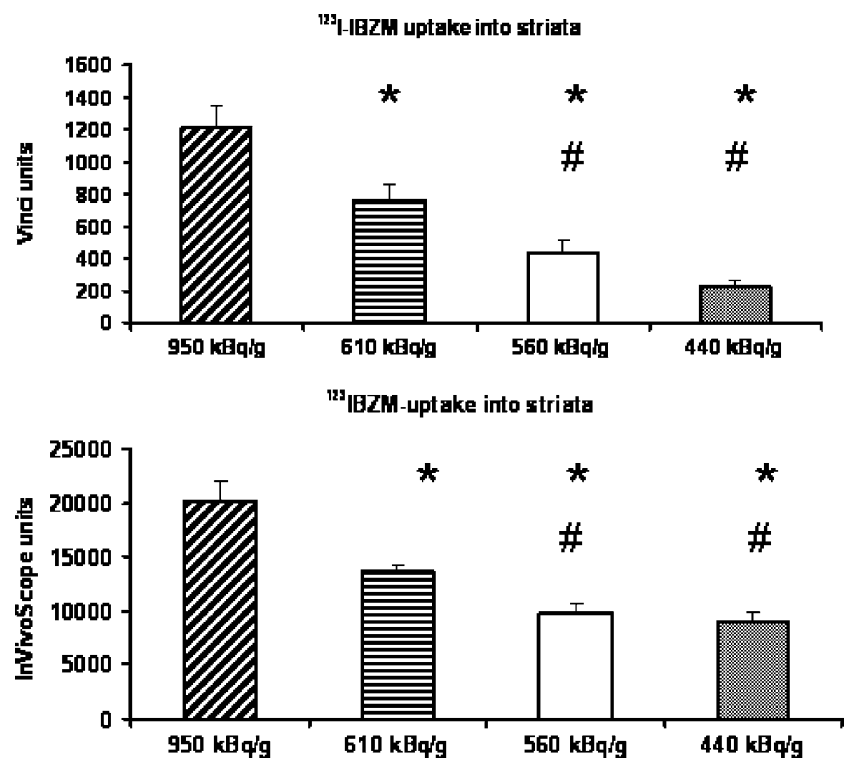

Fig. $4\left[{ }^{123}\right.$ I] IBZM uptake into murine striata. Mean \pm SEM was calculated for each animal from 12 data points (right and left striata) involving six acquisition periods, when the complete set of intensity data at the four activity doses was available. ${ }^{*} p<0.05$ vs $950 \mathrm{kBq} / \mathrm{g}$ body weight. $\# p<0.05$ vs $610 \mathrm{kBq} / \mathrm{g}$ body weight. ANOVA followed by the Student-Newman-Keuls test was used for statistical comparison. See Fig. 2 for further description of the imaging conditions 


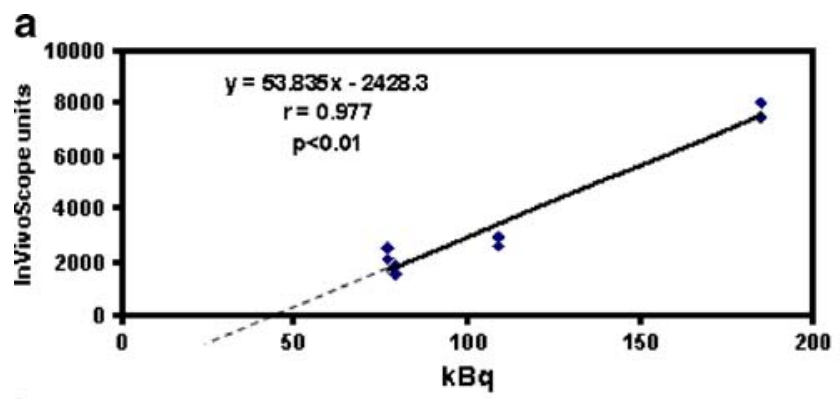

b

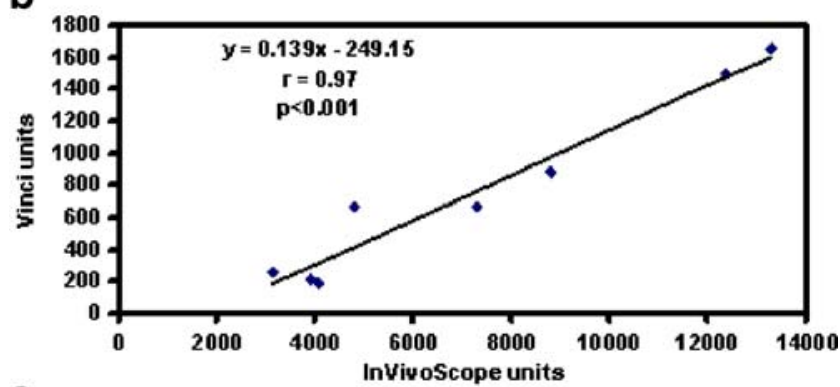

C

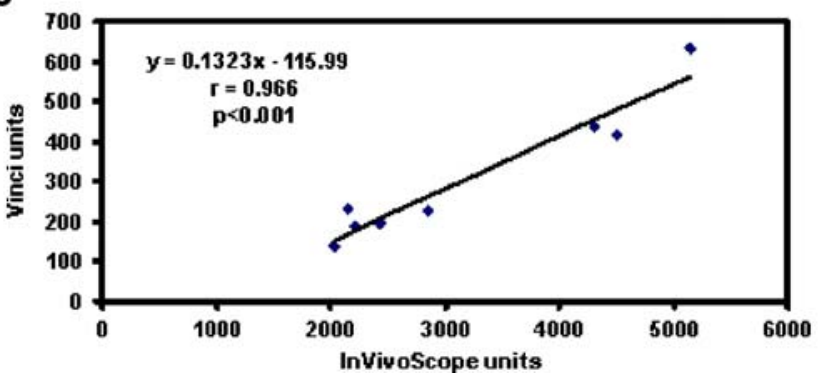

Fig. 5 In vitro uptake of $\left[{ }^{123} \mathrm{I}\right] \mathrm{IBZM}$ versus in vivo imaging data obtained with different processing tools. a Correlation between striatal uptake of $\left[{ }^{123}\right.$ I]IBZM in vivo analysed using the InVivoScope processing tool with the total cerebral activities observed. In vivo data reflect the activity detected in right and left striata of the four animals analysed also in Figs. 2-4. Conditions of the measurements are in accordance with that described in the legend of Fig. 2. The offset for $\mathrm{y}$ (in vivo intensity) $=0$ was determined as $\mathrm{x}_{0} 45 \mathrm{kBq}$ and regarded as the border of detection under the acquisition conditions chosen (100 s acquisition time and 10 steps of rotation). Higher acquisition times should diminish the detection threshold. b, c Correlation between data of striatal accumulation of $\left[{ }^{123} \mathrm{I}\right] \mathrm{IBZM}$ obtained using the Vinci 2.3.1. and InVivoScope processing tools during acquisition periods 3 (b) and 8 (c). Right and left striata of four animals were involved in the calculations

BRwt1 brain weight of first species

BRwt2 brain weight of second species

BDwt2 body weight of second species

Figure 6 shows these activities for different proportions of brain and body weights suggesting that an equivalent visualisation as in a $30 \mathrm{-g}$ mouse can be obtained in a rat of $300 \mathrm{~g}$ body weight, using only the $2-2.5$-fold of the activity applied in mice although the proportion of the body weights is $1: 10$. This calculation however does not include the potential influence of further aspects such as species differences in distribution velocity of the tracers as described previously [33] or species differences in metabolism or carrier kinetics.

Figure 7 shows $\left[{ }^{99 m}\right.$ Tc]HMPAO SPECT images. The tracer allows a visualisation of brain perfusion using an activity of $1.16 \mathrm{MBq} / \mathrm{g}$ even at an acquisition time of $140 \mathrm{~s}$ but not using half of that activity (for maximum intensity projections of $\left[{ }^{123} \mathrm{I}\right] \mathrm{IBZM}$ and $\left[{ }^{99 \mathrm{~m}} \mathrm{Tc}\right] \mathrm{HMPAO}$ SPECT see Supplement 1A and Supplement 1B, respectively).

Cardiac uptake of $\left[{ }^{99 \mathrm{~m}} \mathrm{Tc}\right]$ sestamibi and $\left[{ }^{123} \mathrm{I}\right] \mathrm{IPPA}$

MPS images of the distribution of $\left[{ }^{123}\right.$ I]IPPA are shown in a wild-type mouse during the first $57 \mathrm{~min}$ p.i. in Fig. 8 .

The heart weights of the transgenic animals were enhanced to $193.6 \pm 14.2 \mathrm{mg}$ vs $112.6 \pm 8.25 \mathrm{mg}$ in wildtype mice, while the body weights were $22.8 \pm 1.46 \mathrm{~g}$ and $24 \pm 1.66 \mathrm{~g}$, respectively. The cardiac uptake of $\left[{ }^{99 \mathrm{~m}} \mathrm{Tc}\right]$ sestamibi measured in vitro by means of the activimeter was $6.2 \pm 0.78$ in transgenic and $8.3 \pm 0.99 \mathrm{kBq} / \mathrm{mg}$ in wildtype animals. The SPECT imaging method reflected the alterations in cardiac anatomy as well as the enlargement of the right ventricles in cardiomyopathic hearts found also by means of MR imaging (Fig. 9).

The visualisation of $\left[{ }^{99 \mathrm{~m}} \mathrm{Tc}\right]$ sestamibi in the heart required 4-10-fold higher doses than for the ${ }^{123}$ I-labelled receptor ligands. Figure 10 shows a comparison between two hearts after application of the same activity $(3.8 \mathrm{MBq} / \mathrm{g}$

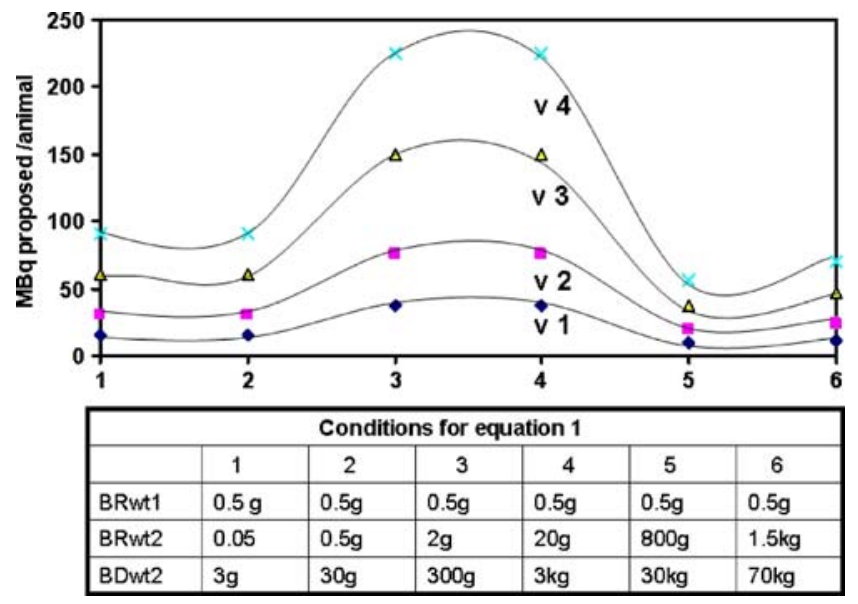

Fig. 6 Approach to estimation of activities for equipotent visualisation of ${ }^{123} \mathrm{I}$-labelled receptor ligands in different species according to Eq. 1. The figure shows activities proposed for the application to different species to obtain a visualisation equipotent to that observed in mice. The numbers 1 to 6 of the x-axis correspond to the conditions listed in the table below the diagram. BRwtl brain weight of the first species, BRwt2 brain weight of the second species, BDwt2 body weight of the second species. The lines connect the doses per animal resulting in visualisation levels $(v)$ corresponding to the visualisation quality expected in mice following application of $0.5 \mathrm{MBq}\left[{ }^{123} \mathrm{I}\right]$ IBZM/g body weight ( $v 1), 1 \mathrm{MBq} / \mathrm{g}$ body weight $(v 2), 2 \mathrm{MBq} / \mathrm{g}$ body weight ( $v 3)$ and $3 \mathrm{MBq} / \mathrm{g}$ body weight $(v 4)$ 
Fig. 7 Uptake of $\left[{ }^{99 m} \mathrm{Tc}\right]$ HMPAO in the murine brain. $\left[{ }^{99 \mathrm{~m}} \mathrm{Tc}\right] \mathrm{HMPAO}$ uptake after application of 0.47 (A) and $1.16 \mathrm{MBq} / \mathrm{g}$ body weight (B). The body weight of the animals was $36 \mathrm{~g}$. Acquisition time of $140 \mathrm{~s}$ and 10 steps of rotation were used for imaging. 1 thyroid gland, 2 salivary gland, 3 lacrimal gland and ducts. Planes of the sections: $a$ coronal, $b$ transversal, $c$ sagittal. Sections Aa and $\mathbf{B} \boldsymbol{a}$ were measured at prone position of the animals, however are shown here in supine position

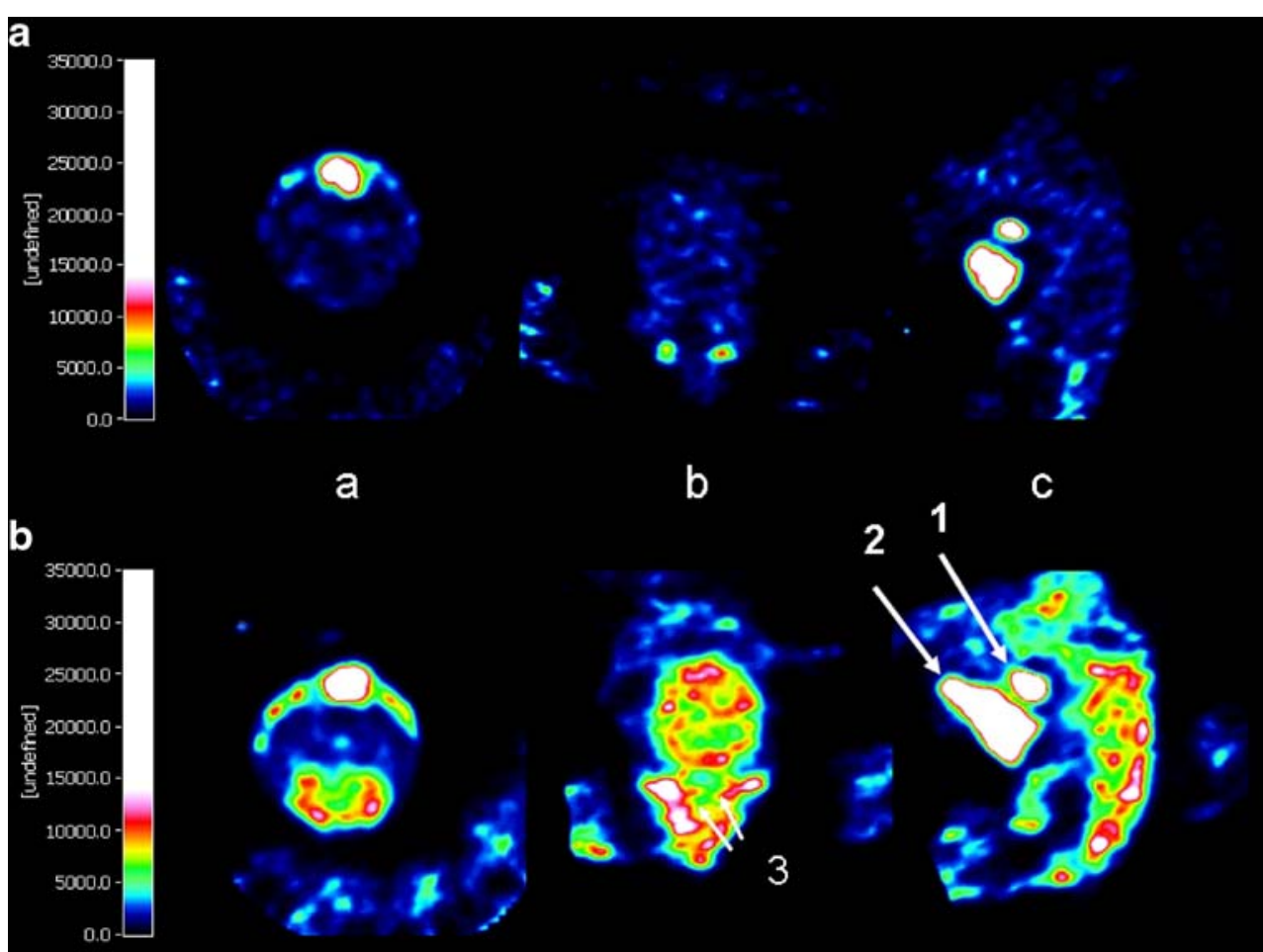

body weight; for maximum intensity projections see Supplement 2A and Supplement 2B). Figure 11 shows real-time yield as kcps per detector and the respective intensity values registered within the total field of view of measurement evaluated by means of the InVivoScope processing tool (periods 1 and 2 in vivo as well as four hearts ex vivo). The high yield in the range of 3-14 kcps/ detector during the in vivo measurements (in comparison to
Fig. 8 Multi-pinhole SPECT of murine heart (wild-type) after application of $\left[{ }^{123}\right.$ I]IPPA.

Images were obtained using the Vinci 2.3.1. processing tool during three consecutive acquisition periods following application of $0.89 \mathrm{MBq} / \mathrm{g}\left[{ }^{123} \mathrm{I}\right] \mathrm{IPPA}$ into a $\mathrm{B} 6 \mathrm{C} 3 \mathrm{~F} 1(\mathrm{EP} 3)$ wild-type mouse with $22 \mathrm{~g}$ body weight. a Short axis view. b Horizontal long axis view. c Vertical long axis view. 1 liver, 2 heart

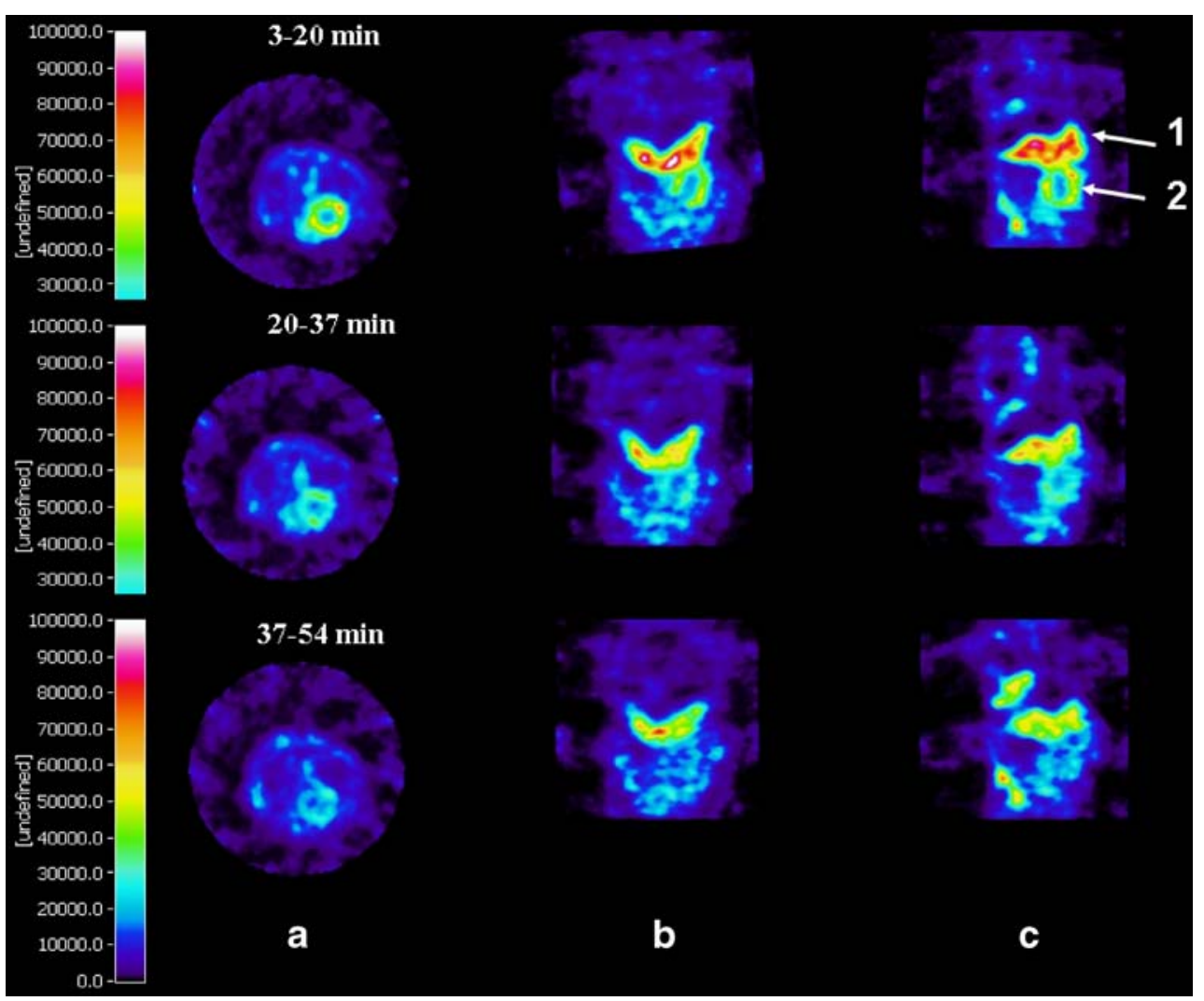


Fig. 9 MR and SPECT images of cardiomyopathic and wildtype hearts. a-d Short axis view of end-diastolic (a and $\mathbf{c}$ ) and end-systolic hearts (b and $\mathbf{d})$ of B6C3F1-Tg(EP3) mouse (a and b) and a wild-type littermate (c and $\mathbf{d}$ ). e, $\mathbf{f}$ Short axis view of a cardiomyopathic (e) and wildtype (f) heart labelled with $\left[{ }^{99 \mathrm{~m}} \mathrm{Tc}\right]$ sestamibi. $\mathbf{g}, \mathbf{h}$ Short axis view of a cardiomyopathic (g) and a wild-type (h) heart labelled with [ ${ }^{123}$ I]IPPA

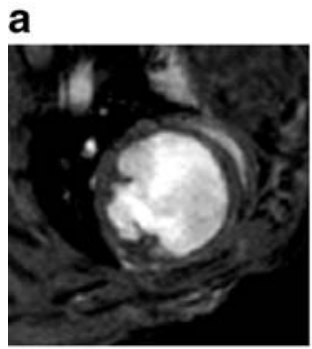

b
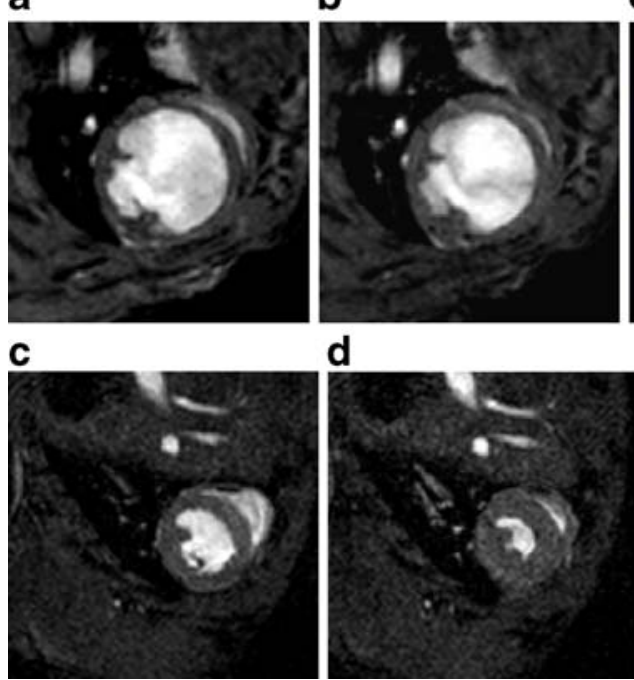

e

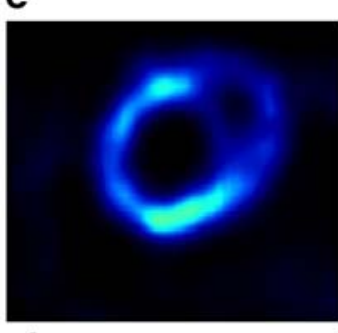

f

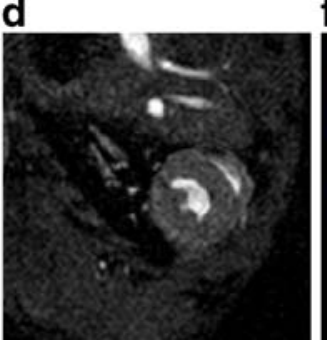

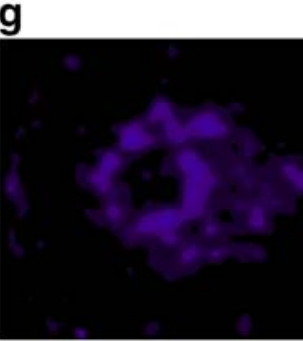

h

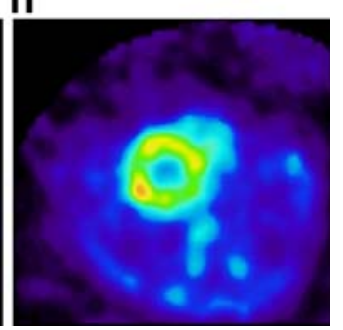

$0.5-2 \mathrm{kcps}$ in the $\left[{ }^{123} \mathrm{I}\right] \mathrm{IBZM}$ brain experiments) is predominantly due to the higher total dose activity applied in the $\left[{ }^{99 \mathrm{~m}} \mathrm{Tc}\right]$ sestamibi experiments. Additionally, a good correlation between in vitro data and in vivo measurements was found for the assessment of the $\left[{ }^{99 \mathrm{~m}} \mathrm{Tc}\right]$ sestamibi using the InVivoScope data processing tool, while data obtained by means of the Vinci 2.3.1. processing tool using only the intensities measured in the left ventricle in vivo showed a lower correlation coefficient (Fig. 12).

The in vitro investigation of hearts from cardiomyopathic and wild-type littermates as well as the uptake of $\left[{ }^{99 m}\right.$ Tc]sestamibi observed during SPECT imaging revealed a $30 \%$ reduction of the cardiac perfusion (Fig. 13). The SUV were calculated referring to the percentage of the activity localised in the heart (InVivoScope, Fig. 12a) to 1\% of the body weight $[25,26]$. Further evaluation of the intracardiac uptake of $\left[{ }^{99 \mathrm{~m}} \mathrm{Tc}\right]$ sestamibi was performed analysing ROIs as depicted in Fig. 14. Both transgenic and wild-type mice showed a heterogeneous uptake of $\left[{ }^{99 \mathrm{~m}} \mathrm{Tc}\right]$ sestamibi with the lowest values in the apical region and right ventricle. A markedly lower fraction of $\left[{ }^{99 \mathrm{~m}} \mathrm{Tc}\right]$ sestamibi was found in the septal apical as well as in the lateral basal and apical regions in transgenic hearts compared to wild-type hearts.
Fig. 10 Images of cardiomyopathic and wild-type hearts: short axis and horizontal and vertical long axis views after application of $\left[{ }^{99 \mathrm{~m}} \mathrm{Tc}\right]$ sestamibi. a A cardiomyopathic heart with cardiac overexpression of the $\mathrm{EP}_{3}$ receptor. Body weight of the mouse was $22 \mathrm{~g}$ and heart weight $187 \mathrm{mg}$. $S A$ short axis view, HLA horizontal long axis view, $V L A$ vertical long axis view. b A wild-type mouse with a body weight of $24 \mathrm{~g}$ and $138 \mathrm{mg}$ heart weight. Measurements were performed using $150 \mathrm{~s}$ acquisition time and 10 steps of rotation after application of $3.8 \mathrm{MBq} / \mathrm{g}$ body weight $\left[{ }^{99 \mathrm{~m}} \mathrm{Tc}\right]$ sestamibi
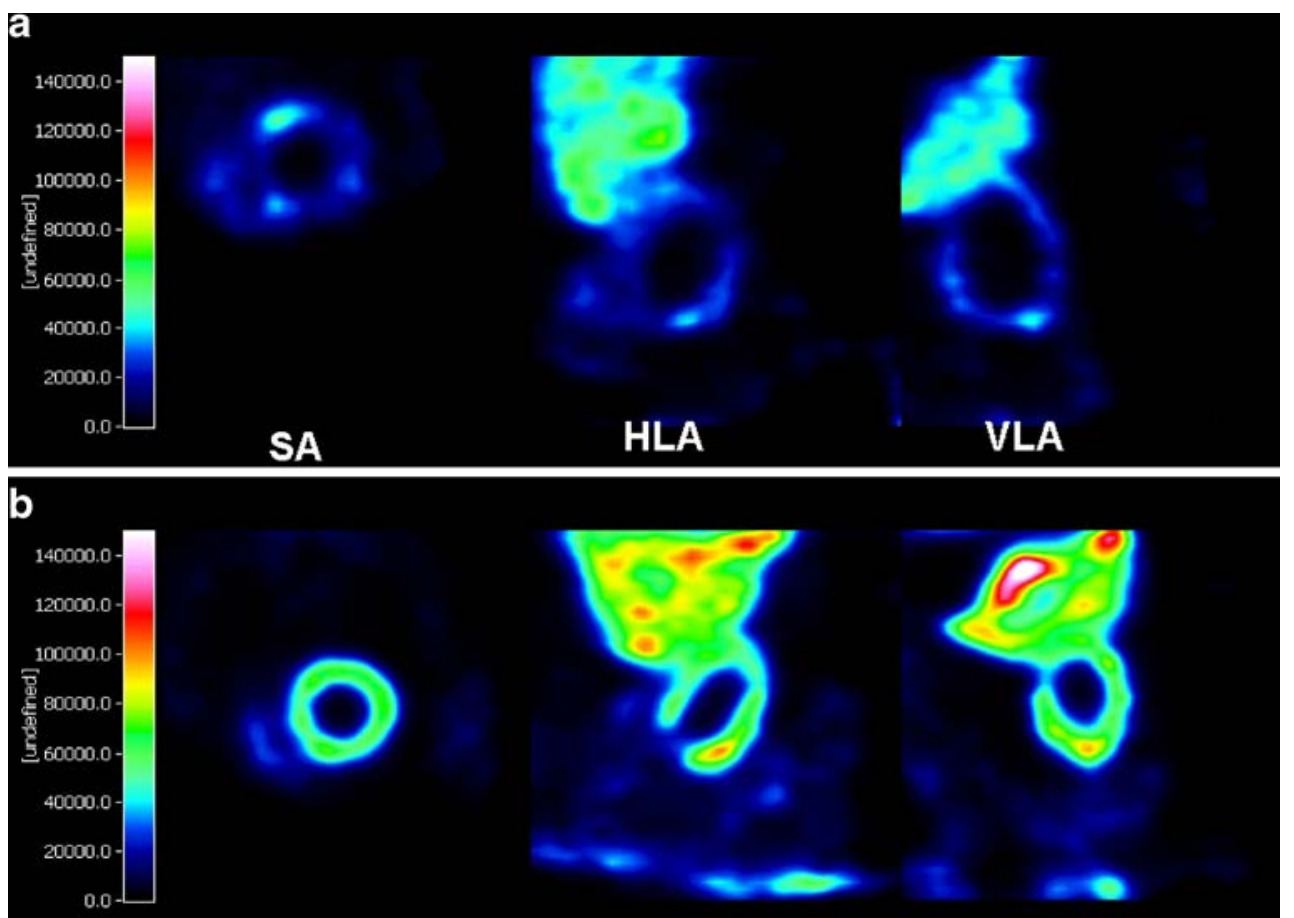


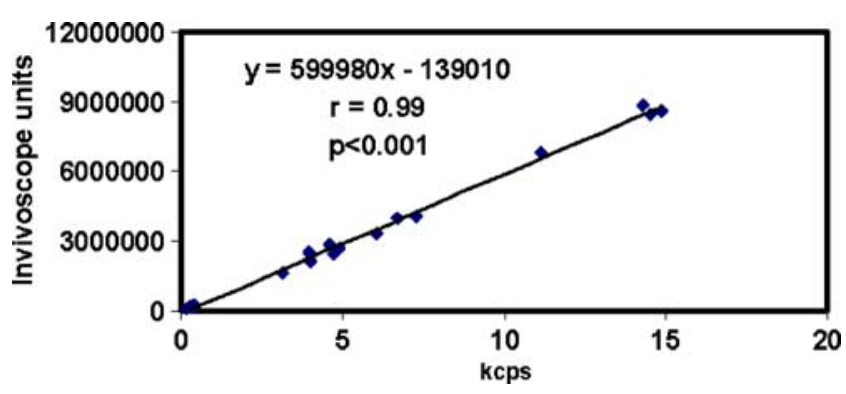

Fig. 11 Yield obtained per detector during measurements of cardiac uptake of $\left[{ }^{99 \mathrm{~m}} \mathrm{Tc}\right]$ sestamibi. Data of 14 mean values of measurements in phase 1 and phase 2 and data of four ex vivo heart measurements (the four lowest values depicted) are correlated with arbitrary units obtained using the InVivoScope data processing tool. Kcps reflecting the average of counts displayed on the screen during all acquisition periods $(150 \mathrm{~s}$ and 10 steps of rotation) are correlated with the results of the evaluation by means of the InVivoScope data processing tool. The regression line demonstrates the linearity of the multi-pinhole device

\section{Discussion}

The present study provides a first direct quantitative comparison of volume-based evaluation of in vivo imaging data and in vitro data on the uptake of SPECT tracers in murine brain and heart using $\left[{ }^{123} \mathrm{I}\right] \mathrm{IBZM}$ and $\left[{ }^{99 \mathrm{~m}} \mathrm{Tc}\right]$ sestamibi, respectively. Thresholds of detection are calculated for tracers with different distribution patterns in murine brain and in the heart, respectively, for the conditions of the multi-pinhole SPECT system employed. Moreover it is shown that the multi-pinhole SPECT method is able to identify differences in the range of $20 \%$ of the maximal uptake in the dose range between $950 \mathrm{kBq} / \mathrm{g}$ and $440 \mathrm{kBq} / \mathrm{g}$ employed in this study. The in vivo uptake of $\left[{ }^{123} \mathrm{I}\right] \mathrm{IPPA}$ in mice is visualised for the first time.

\section{Brain investigations}

Dopamine $\mathrm{D}_{2}$ receptor ligands such as $\left[{ }^{123} \mathrm{I}\right] \mathrm{IBZM}$ or $\left[{ }^{11} \mathrm{C}\right]$ raclopride belong to the preferred tools used to investigate the performance of small animal SPECT and PET imaging devices with respect to in vivo visualisation of brain structures and signal transduction [26-28, 30]. That is due to the fact that dopamine $\mathrm{D}_{2}$ receptors are found with a high density in the striatum as a compactly shaped telencephalic part of the brain, providing a well-defined volume of interest ranging from 30 to $60 \mathrm{mg}$ (both striata in summary) in adult mice surrounded by a large zone of lower dopamine $\mathrm{D}_{2}$ receptor density and relatively low nonspecific binding.

Evaluations of PET and SPECT in vivo imaging data in small animal models with the aim of developing algorithms for tracer quantification or coregistration with other imaging data have been described previously [24, 36-40]. The literature includes comparisons with autoradiographic measurements or other semi-quantitative reference tissue methods for brain, heart and some tumour models of different localisations [39, 41]. In our MPS $\left[{ }^{123} \mathrm{I}\right] \mathrm{IBZM}$ measurements, the activity bound non-specifically in the whole brain decreases at the end of the observation period of $3 \mathrm{hs}$ to $20 \%$ of the initial values, while the activity bound specifically reached an equilibrium during the fifth acquisition period. This is in agreement with the time course reported in a previous pinhole SPECT study of $\left[{ }^{123} \mathrm{I}\right] \mathrm{IBZM}$ in mouse models [28] as well as with an ex vivo study [40]. The imaging data evaluated with the InVivoScope and Vinci 2.3.1. data processing tools allowed us to distinguish differences upwards from $20 \%$ of maximal tracer amount accumulated in the brains in the dose range between $440 \mathrm{kBq} / \mathrm{g}$ and $950 \mathrm{kBq} / \mathrm{g}$. The least-squares linear fit for the comparison of in vitro and in vivo uptake of $\left[{ }^{123} \mathrm{I}\right] \mathrm{IBZM}$ allowed us to reveal that this percentage corresponds to a total cerebral activity of $116 \mathrm{kBq} / \mathrm{g}$. The estimate involves the assumption that approximately $50 \%$ of the tracer detected in the brain binds to receptors in the striata. A lower ratio of striatal to total cerebral activity would result in higher activity values.

There are only a few reports on measurements of $\left[{ }^{123} \mathrm{I}\right]$ IBZM in the murine brain using SPECT or multi-pinhole SPECT, respectively. More attention has been paid to ligands of dopamine transporters using $\left[{ }^{123} \mathrm{I}\right] \mathrm{FP}-\mathrm{CIT}$ or

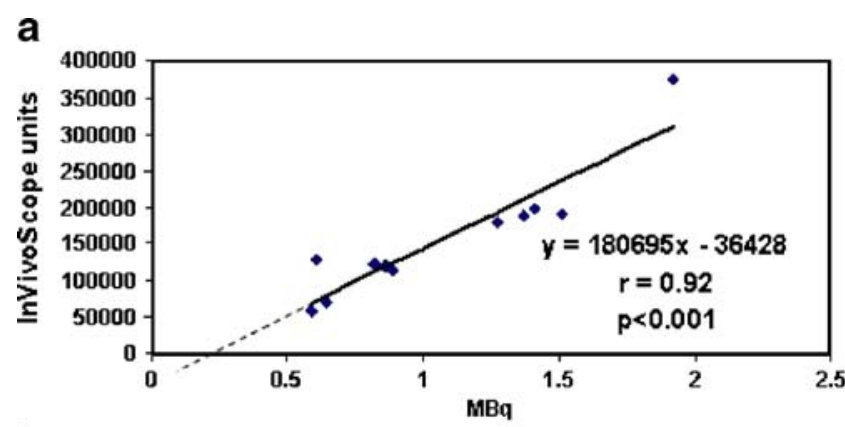

b

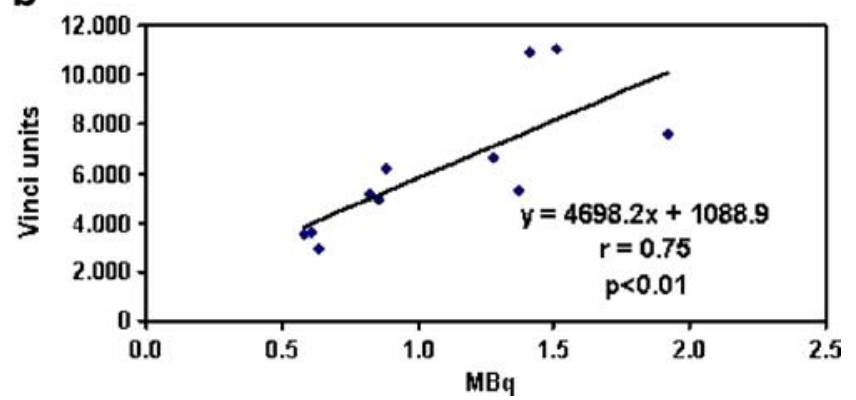

Fig. 12 Correlation of cardiac accumulation of $\left[{ }^{99 \mathrm{~m}} \mathrm{Tc}\right]$ sestamibi in vitro and in vivo. a Comparison of in vivo data obtained using the InVivoScope data processing tool with in vitro activities in transgenic and wild-type animals. b Comparison of in vivo data obtained using the Vinci 2.3.1. data processing tool with in vitro activities in transgenic and wild-type animals 


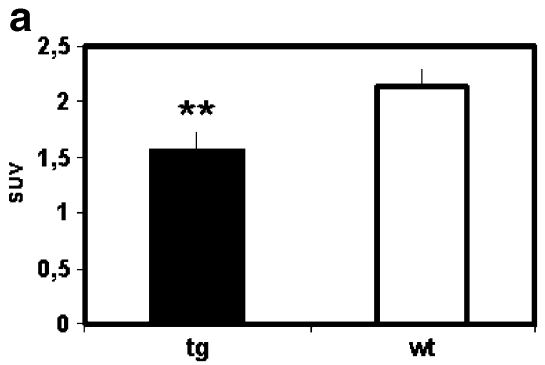

Fig. 13 SUV in B6C3F1- $\operatorname{~gg}(\mathrm{EP} 3)$ and wild-type mice in vitro and in vivo. Comparison of $\left[{ }^{99 \mathrm{~m}} \mathrm{Tc}\right]$ sestamibi uptake in the heart: in vitro (a) and in vivo (b). $\left[{ }^{99 \mathrm{~m}} \mathrm{Tc}\right]$ sestamibi accumulations in five $\mathrm{B} 6 \mathrm{C} 3 \mathrm{~F} 1-\mathrm{Tg}$ (EP3) mice and their wild-type littermates were used for calculation of cardiac SUV. Means \pm SEM are shown. Asterisks indicate $p<0.005$ calculated for the two-tailed paired Student's $t$ test. Calculation of

${ }^{99 \mathrm{~m}}$ Tc-labelled ligands such as $\left[{ }^{99 \mathrm{~m}} \mathrm{Tc}\right] \mathrm{TRODAT}[25,30$, $39,42,46]$. This may be due to the fact that the preparation of $\left[{ }^{123} \mathrm{I}\right] \mathrm{FP}-\mathrm{CIT}$, which is commercially available, contains less ethanol than preparations of $\left[{ }^{123} \mathrm{I}\right] \mathrm{IBZM}$ on the one

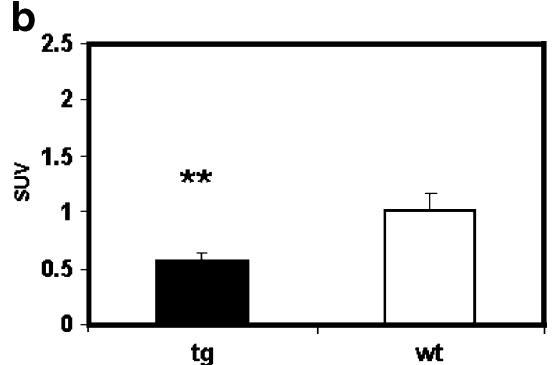

standard uptake in vitro was performed using activities and weights determined in excised hearts. Calculation of in vivo data was performed using activities determined using the regression line in Fig. 12a referring to the apparent heart volume calculated by the InVivoScope tool. SUV in vitro is given without dimension and SUV in vivo has the dimension arbitrary units (InVivoScope)/MBq

hand and shows higher specific activity on the other hand. This allows easier i.v. application and promises a favourable proportion of occupancy of the target structures at appropriate visualisation quality. A direct comparison of in
Fig. 14 Comparison of regional cardiac accumulation of $\left[{ }^{99 \mathrm{~m}} \mathrm{Tc}\right]$ sestamibi in cardiomyopathic and wild-type mice. a Horizontal long axis view. b Vertical long axis view. ROI: 1 lateral basal, 2 lateral apical, 3 apical, 4 septal apical, 5 septal basal, 6 right ventricle, 7 anterior basal, 8 anterior apical, 9 apical, 10 inferior apical, 11 inferior basal. Means \pm SEM are shown. Asterisks indicate differences between the respective ROIs between cardiomyopathic hearts and the hearts of the wild-type littermates with $p<0.05 ; 5-11$ data points observed in the acquisition periods $1-3$ were used for the calculation of each mean value

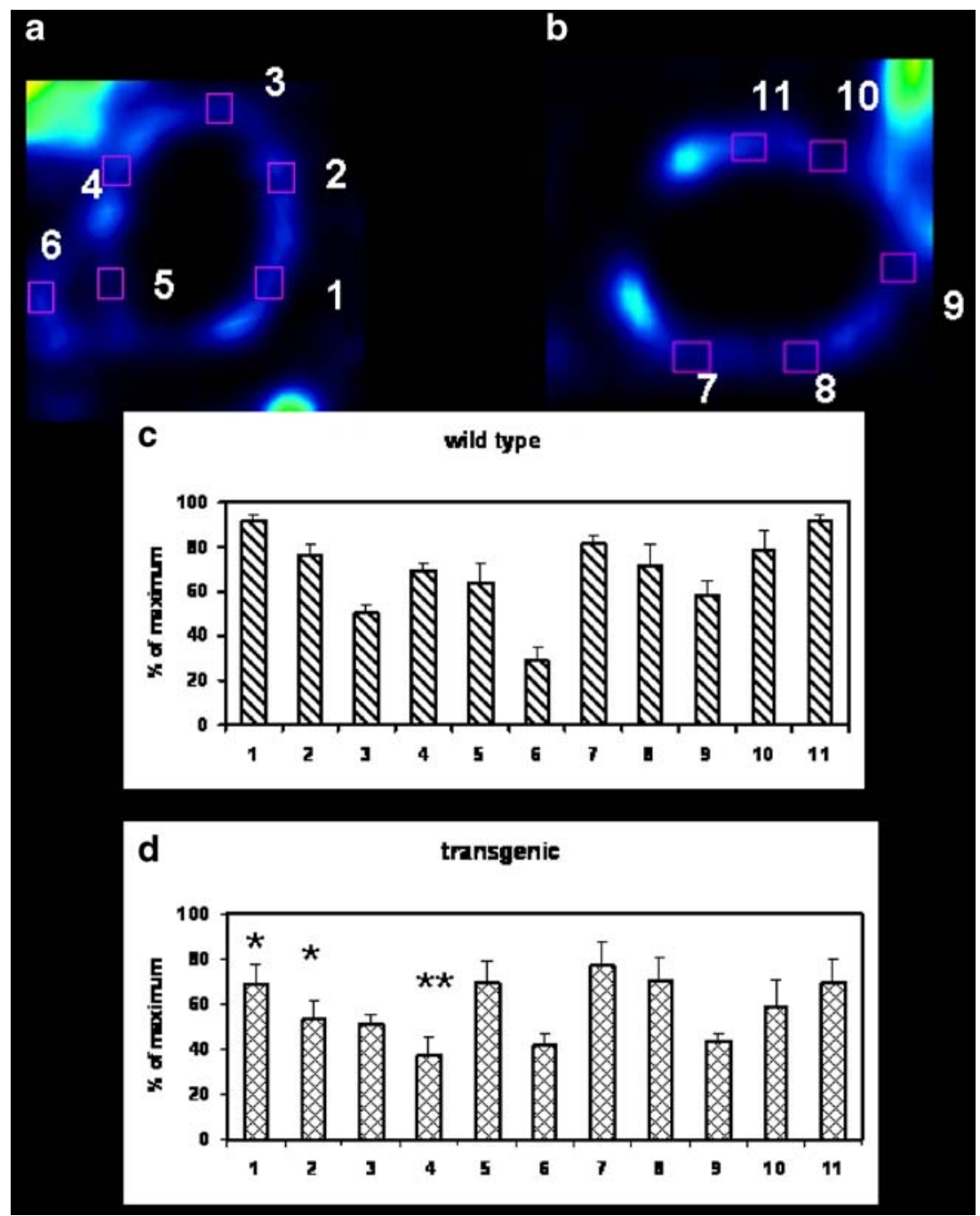


vitro and in vivo measurements in murine models (or other rodents) neither exists for $\left[{ }^{123} I\right] I B Z M$ nor for dopamine $D_{2}$ receptors labelled with positron-emitting isotopes. The fraction of the total cerebral $\left[{ }^{123} \mathrm{I}\right] \mathrm{IBZM}$ found in the striata during our experiments was calculated for the different observation times to be in the range between 25 and $50 \%$. Studies analysing ligand binding following chemical impairment of the target region or with displacement by highly specific antagonists of receptors or transporters describe alterations in the receptor occupancy of $50-90 \%$ [27, 43]. Chalon et al. reported in 1990 [43] for in vivo/ex vivo studies using [ $\left.{ }^{125} \mathrm{I}\right] \mathrm{IBZM}$ a $45 \%$ increase of the binding of the tracer after pre-treatment with haloperidol. Singhaniyom et al. [44] observed a displacement of $\left[{ }^{125} \mathrm{I}\right] \mathrm{IBZM}$ by about $72 \%$ following in vivo pre-treatment with antagonists of the dopamine $\mathrm{D}_{2}$ receptor in mice. Under such conditions multipinhole SPECT already provides a suitable tool for in vivo characterisation of signal transduction units.

Using the InVivoScope data processing tool, we found $4.2 \pm 0.27$ of the injected dose of $\left[{ }^{123} \mathrm{II}\right] \mathrm{BZM}$ per $\mathrm{g}$ brain tissue. For an activity of $109 \mathrm{kBq} /$ brain as measured in one of our experiments at a specific activity of $74 \mathrm{TBq} / \mathrm{mmol}$ and $50 \%$ of total cerebral activity in the striata $(30 \mathrm{mg}$ wet weight), $24.5 \mathrm{nmol} / \mathrm{kg}\left[{ }^{123} \mathrm{I}\right] \mathrm{IBZM}$ are bound. That would be close to half of the $B_{\max }$ value in vitro but below the $\mathrm{ED}_{50}$ described for IBZM previously with $37 \mathrm{nM}[47,48]$. The receptor occupancy calculated according to the equation given by Hume et al. [23] with occupancy = activity $\div$ weight $*$ ED50 $*$ specific activity + activity was $18.5 \pm 2.5 \%$ for all $\left[{ }^{123} \mathrm{I}\right] \mathrm{IBZM}$ experiments (range: 25 $13 \%$ ). This confirms our previous estimation using preliminary SPECT data of $\left[{ }^{123} \mathrm{I}\right] \mathrm{IBZM}$ uptake and the assumption that at activities of $\leq 20 \mathrm{MBq} /$ animal (in mice weighing 50 $25 \mathrm{~g})$ the concentration of IBZM stays below $\mathrm{ED}_{50}$, but for displacement studies with a low mass effect it is necessary to work with higher specific activities than the reference 74 $\mathrm{TBq} / \mathrm{mmol}$ used in our calculations [30]. This reference is the lower boundary of the specific activity guaranteed by the manufacturer. The concentration in non-striatal cerebral tissue in the sample described above was $1.62 \mathrm{nmol} / \mathrm{kg}$ at the same time resulting in a ratio of specific to non-specific binding of 15. Meyer et al. [40] described a ratio of 17 in autoradiographic studies in mice if working with a ketamine/ xylazine (without isofluorane) anaesthesia comparable to that which we applied. The ratio was markedly lower if isoflurane was included in the anaesthesia. An occupancy below $5 \%$ can be achieved with higher specific activities as described recently [42].

The dose-dependent increase in the uptake of $\left[{ }^{123} \mathrm{I}\right]$ IBZM during the eight observation periods suggests that the activity doses applied are in the linear range of the doseresponse curve. This allowed identification of the border of detection for the difference in the uptake in regard to different injection doses without impairment by saturation effects.

The activity threshold for the visualisation of in vivo uptake in the brain for a tracer like $\left[{ }^{123} \mathrm{I}\right] \mathrm{IBZM}$ with a small target region and a relatively high specific activity was $45 \mathrm{kBq}$ (and $6 \mathrm{kBq}$ ex vivo; data not shown; using $100 \mathrm{~s}$ acquisition time and 10 step rotation mode in our camera system) as revealed by the offset of the regression line for the comparison between in vivo and in vitro data at $y=0$. The comparison of the doses recommended to be applied in different species for several visualisation levels is verified for ligands of dopamine transporters and receptors in mice and rats by our own data. The results agree also with the calculations by Kung et al. [47, 48]. If measurements of species with larger geometric dimensions require a larger radius of rotation further correction factors are necessary. Weber et al. [49] described for a triple-headed pinhole SPECT system how spatial resolution and sensitivity change with the increase in the distance between detectors and target region. Taking these alterations into account for a special multi-pinhole system, also the doses necessary for equipotent visualisation would need an additional correction factor. An increased role of attenuation in larger species would also require further modification of the data [41]. For a tracer such as $\left[{ }^{99 \mathrm{~m}} \mathrm{Tc}\right] \mathrm{HMPAO}$ with homogeneous distribution through the target organ as well as a specific activity $<5 \%$ [50] of that of the receptor ligand investigated in our study, the threshold of detection is $2-10$ fold higher.

$\left[{ }^{99 \mathrm{~m}} \mathrm{Tc}\right]$ HMPAO $\left(\left[{ }^{99 \mathrm{~m}} \mathrm{Tc}\right]\right.$ exametazime $[(\mathrm{RR}, \mathrm{SS}])-4,8-$ diaza-3,6,6,9-tetramethylundecane-2,10-dione bisoxime) is an uncharged, low molecular weight, lipophilic complex that easily crosses the blood-brain barrier [51]. It is known that in man 3-5 to 7\% of HMPAO injected pass into the brain by passive diffusion during the first minutes after injection. In humans it remains for $24 \mathrm{~h}$ in the brain, probably trapped inside cells via a reaction with glutathione [52], and is not preferentially bound to a specific region of the brain.

\section{Cardiac investigations}

Altered activity requirements were also revealed during the imaging of the perfusion tracer $\left[{ }^{99 \mathrm{~m}} \mathrm{Tc}\right]$ sestamibi (4-10-fold of that necessary for the $\left[{ }^{123} \mathrm{I}\right] \mathrm{IBZM}$ experiments). The lipophilic compound $\left[{ }^{99 \mathrm{~m}} \mathrm{Tc}\right]$ sestamibi is a cationic complex which is accumulated in tissues rich in mitochondria like liver and heart and trapped in the mitochondrial matrix [53]. Accumulations of $1.2 \%$ of the dose were reported for silent myocardium and $1.5 \%$ under stress [51]. The compound enters the heart by passive diffusion and correlates well with regional perfusion under conditions of normal load. It shows almost no redistribution [54] under 
these conditions, while its extraction at high coronary flow or under hypoxic conditions is not proportional to coronary perfusion [51].

Our model of cardiac overexpression of the $\mathrm{EP}_{3}$ receptor, a subtype of the prostaglandin receptor, showed a decreased cardiac accumulation of $\left[{ }^{99 \mathrm{~m}} \mathrm{Tc}\right]$ sestamibi in the transgenic animals compared to their wild-type littermates. This suggests a contribution of disturbances in perfusion or mitochondrial dysfunction [55] to potential changes in the uptake of metabolic tracers-in our case the long chain fatty acid $\left[{ }^{123} \mathrm{I}\right] \mathrm{IPPA}[14,56]$.

Quantitative comparison of in vitro and in vivo uptake of $\left[{ }^{99 \mathrm{~m}} \mathrm{Tc}\right]$ sestamibi in murine hearts observed with SPECT cameras is not available in the literature to our knowledge. However, semi-quantitative approaches have been reported by Zhou et al. [57] for investigations of [ $\left.{ }^{99 m} \mathrm{Tc}\right]$ sestamibilabelled regionally ischaemic rat hearts included in dual isotope studies (140 and $247 \mathrm{keV}$ ) on the tracking of $\left[{ }^{111}\right.$ In]-labelled stem cells [41, 57]. Zhou et al. employed a triple-headed pinhole camera for the detection of $\left[{ }^{99 \mathrm{~m}} \mathrm{Tc}\right]$ sestamibi (74 MBq/animal) and could show the grafting of the stem cells during a 96-h observation period. A bull's eye plot was used for the evaluation of regional cardiac distribution of ${ }^{99 \mathrm{~m}} \mathrm{Tc}$ and ${ }^{111} \mathrm{In}$. Left ventricular visualisation of the tracers was obtained in a similar quality as in our experiments. Beekman et al. [58] were able to visualise murine heart perfusion with a submillimetre resolution after injection of $222 \mathrm{MBq}\left[{ }^{99 \mathrm{~m}} \mathrm{Tc}\right]$ tetrofosmin. However, quantitative approaches to the correlation of in vivo SPECT data with in vitro measurements of the tracer uptake are rather available for sestamibi and other perfusion tracers in porcine and canine models [59, 60]. Da Silva et al. [60] drew an offset of $7-11 \mathrm{kBq} / \mathrm{g}$ heart weight from the correlation of in vivo SPECT data of $\left[{ }^{99 \mathrm{~m}} \mathrm{Tc}\right]$ sestamibi uptake in porcine hearts with ex vivo data. That would give a detection threshold of $1 \mathrm{MBq}$ total uptake for a $150 \mathrm{-g}$ heart. For our murine hearts in the multi-pinhole system we found a threshold of $200 \mathrm{kBq} /$ heart. That corresponds for hearts with a size between 100 and $200 \mathrm{mg}$ to $1-2 \mathrm{MBq} / \mathrm{g}$. Compared to the offset found in the porcine model the threshold for the uptake per murine heart would be lower, but the offset per g heart weight would be 150-350-fold higher. However, the ratio of the body weights of mouse and pig would be 1:1,000.

Estimates of the whole-body dose in SPECT [61] are given with a range from less than 2 cGy $(160 \mathrm{MBq}$ of ${ }^{99 \mathrm{~m}} \mathrm{Tc}$; biological half-life $1 \mathrm{~h}$ ) in rats to $90 \mathrm{cGy}(740 \mathrm{MBq}$ in $30 \mathrm{~g}$-mice assuming a residence time of $3.2 \mathrm{~h}$ ) [41]. The activity of $\left[{ }^{99 \mathrm{~m}} \mathrm{Tc}\right]$ sestamibi applied in our experiment comprised maximally $30 \%$ of this amount and on average $15 \%$. Funk et al. [61] reported theoretical values of the whole-body doses from phantom measurements corresponding to the conditions of biological experiments in the range between 6 and $90 \mathrm{cGy}$ for mice and 1-27 cGy for rats and a $\mathrm{LD}_{50}$ of $7 \mathrm{~Gy} / 30 \mathrm{~d}$ for mice.

Transgenic B6C3F1(EP3) mice show an increase of left ventricular mass, end-diastolic and end-systolic volumes as well as a significant decrease in left ventricular ejection fraction and $\mathrm{dP} / \mathrm{dt}$, as found recently [29]. These alterations were already obvious in 5- to 7-week-old animals [29]. Our data support the maintenance of the cardiomyopathic alterations in the 11- to 17-week-old mice with $8.6 \pm$ $0.36 \mathrm{mg}$ heart weight/g body weight in comparison to $4.6 \pm 0.14 \mathrm{mg} / \mathrm{g}$ in wild-type littermates.

The analysis of the hearts excised in transgenic and wildtype littermates following the SPECT measurements revealed that the uptake of $\left[{ }^{99 \mathrm{~m}} \mathrm{Tc}\right]$ sestamibi was $30 \%$ lower in cardiomyopathic animals than in wild-type animals. This difference is confirmed if the SUV is calculated for in vivo conditions. The segmental analysis of ROIs reveals heterogeneity of $\left[{ }^{99 \mathrm{~m}} \mathrm{Tc}\right]$ sestamibi accumulation in both cardiomyopathic and wild-type hearts with lowest uptake in the apical regions, but reduced accumulation of $\left[{ }^{99 m} \mathrm{Tc}\right]$ sestamibi in the septal and lateral part of the left ventricle of transgenic mice compared to the wild-type animals.

$\left[{ }^{123} \mathrm{I}\right] \mathrm{IPPA}$, in contrast to $\left[{ }^{99 \mathrm{~m}} \mathrm{Tc}\right]$ sestamibi or $\left[{ }^{99 \mathrm{~m}} \mathrm{Tc}\right]$ HMPAO, is accumulated in the target tissue achieving $39 \%$ of the injected dose per $g$ heart weight [56] by an active process via a CD36 protein acting as a carrier of long chain fatty acids $[14,62]$. It is not clear whether the paradoxical hypertrophic response of the heart to the overexpression of $\mathrm{EP}_{3}$ receptors, which are known to mediate cardiac protection, is related to these processes. Although an increased phosphorylation of the S6 ribosomal protein has been observed, and it is known to correlate with an enhanced protein synthesis, the kind of relation between $\mathrm{EP}_{3}$ overexpression and morphological and metabolic alterations associated with the cardiomyopathic properties of these hearts has not been characterised. In contrast, alterations in the parameters of contractility and cardiac function can be explained by mediation by the known signalling pathways via $\mathrm{G}_{\mathrm{i}}$-coupled receptors. The imaging of the uptake of long chain fatty acids by MPS methods provides the possibility to investigate such regulatory processes and their metabolic consequences in vivo.

The present investigations support the theory that the multi-pinhole SPECT device in combination with suitable data processing tools is capable of visualising such alterations and quantifying metabolic processes and ligand binding in different target organs of mice in a feasible dose range. Recently, the quantitative approach which can be used in experimental models has received further support by a plenitude of reports concerning attenuation [63], algorithms for improving reconstruction image quality $[64,65]$, further improvement of the pinhole collimator design $[66,67]$ and multimodal approaches used for PET 
and SPECT investigations [36, 68]. The small scale of murine models is not only a disadvantage for visualisation, but also offers advantages for example in relation to the attenuation [41]. The multi-pinhole approach in contrast to small animal PET allows multi-isotope investigations and provides advantages by a more favourable whole-body dose during the use of SPECT isotopes in comparison to positron emitters, shown by favourable MIRD $S$ values [61], availability of SPECT isotopes and high specific activity for receptor and transporter ligands exceeding frequently those of PET radiopharmaceuticals. The rising availability of CT/SPECT as well as the use of a gated mode of measurements during cardiac investigations extend the access to in vivo information on biochemistry, molecular and cell biology as well as physiology.

Acknowledgments The authors gratefully acknowledge the very helpful assistance of Mrs. Heike Friedrich, Mrs. Christina Schooss and Mr. Anton Fixmann. We address special thanks to Dr. Dagmar Salber, Prof. Karl-Josef Langen and Prof. Jon N. Shah for their interest and support in our work in the Departments of Nuclear Medicine and Magnetic Resonance Imaging.

Open Access This article is distributed under the terms of the Creative Commons Attribution Noncommercial License which permits any noncommercial use, distribution, and reproduction in any medium, provided the original author(s) and source are credited.

\section{References}

1. Beekman FJ, McElroy DP, Berger F, Gambhir SS, Hoffman EJ, Cherry SR. Towards in vivo nuclear microscopy: iodine-125 imaging in mice using micro-pinholes. Eur J Nucl Med Mol Imaging 2002;29:933-8.

2. Schramm NU, Ebel G, Engeland U, Schurrat T, Béhé M, Behr TM. High-resolution SPECT using multipinhole collimation. IEEE Trans Nucl Sci 2003;50:315-20.

3. Wu MC, Gao DW, Sievers RE, Lee RJ, Hasegawa BH, Dae MW. Pinhole single-photon emission computed tomography for myocardial perfusion imaging of mice. J Am Coll Cardiol 2003;42:576-82.

4. Goertzen AL, Jones DW, Seidel J, Li K, Green MV. First results from the high-resolution mouseSPECT annular scintillation camera. IEEE Trans Med Imaging 2005;24:863-7.

5. Ostendorf B, Scherer A, Wirrwar A, Hoppin JW, Lackas C, Schramm NU, et al. High-resolution multipinhole single-photonemission computed tomography in experimental and human arthritis. Arthritis Rheum 2006;54:1096-104.

6. Beckmann N, Kneuer R, Gremlich HU, Karmouty-Quintana H, Blé FX, Müller M. In vivo mouse imaging and spectroscopy in drug discovery. NMR Biomed 2007;20:154-85.

7. Arveschoug AK, Bertelsen H, Vammen B, Brøchner-Mortensen J. Preoperative dual-phase parathyroid imaging with tc-99msestamibi: accuracy and reproducibility of the pinhole collimator with and without oblique images. Clin Nucl Med 2007;32:9-12.

8. Steele PP, Kirch DL, Koss JE. Comparison of simultaneous dualisotope multipinhole SPECT with rotational SPECT in a group of patients with coronary artery disease. J Nucl Med 2008;49:1080-9.
9. Freed M, Kupinski MA, Furenlid LR, Wilson DW, Barrett HH. A prototype instrument for single pinhole small animal adaptive SPECT imaging. Med Phys 2008;35:1912-25.

10. Fujii $H$, Iwasaki R, Ogawa $K$, Hashimoto J, Nakamura K, Kunieda E, et al. Evaluation of parathyroid imaging methods with $99 \mathrm{mTc}-\mathrm{MIBI}$ - the comparison of planar images obtained using a pinhole collimator and a parallel-hole collimator (in Japanese). Kaku Igaku 1999;36:425-33.

11. Saji H, Tsutumi D, Magata Y, Iida Y, Konishi J, Yokoyama A. Preparation and biodistribution in mice of [11C]carfentanil: a radiopharmaceutical for studying brain mu-opioid receptors by positron emission tomography. Ann Nucl Med 1992;6:63-7.

12. Green LA, Gambhir SS, Srinivasan A, Banerjee PK, Hoh CK, Cherry SR, et al. Noninvasive methods for quantitating blood time-activity curves from mouse PET images obtained with fluorine-18-fluordeoxyglucose. J Nucl Med 1998;39:729-34.

13. Müller C, Forrer F, Schibli R, Krenning EP, de Jong M. SPECT study of folate receptor-positive malignant and normal tissues in mice using a novel 99mTc-radiofolate. J Nucl Med 2008;49:310-7.

14. Coburn CT, Knapp FF Jr, Febbraio M, Beets AL, Silverstein RL, Abumrad NA. Defective uptake and utilization of long chain fatty acids in muscle and adipose tissues of CD36 knockout mice. J Biol Chem 2000;275:32523-9.

15. Gainkam LO, Huang L, Caveliers V, Keyaerts M, Hernot S, Vaneycken I, et al. Comparison of the biodistribution and tumor targeting of two $99 \mathrm{mTc}$-labeled anti-EGFR nanobodies in mice, using pinhole SPECT/micro-CT. J Nucl Med 2008;49:788-95.

16. Seitz U, Wagner M, Vogg AT, Glatting G, Neumaier B, Greten $\mathrm{FR}$, et al. In vivo evaluation of 5-[(18)F]fluoro-2'-deoxyuridine as tracer for positron emission tomography in a murine pancreatic cancer model. Cancer Res 2001;61:3853-7.

17. Slavine NV, Antich PP. Practical method for radioactivity distribution analysis in small-animal PET cancer studies. Appl Radiat Isot 2008;66:1861-9.

18. Carlson SK, Classic KL, Hadac EM, Dingli D, Bender CE, Kemp $\mathrm{BJ}$, et al. Quantitative molecular imaging of viral therapy for pancreatic cancer using an engineered measles virus expressing the sodium-iodide symporter reporter gene. AJR Am J Roentgenol 2009;192:279-87.

19. Miot-Noirault E, Vidal A, Auzeloux P, Madelmont JC, Maublant J, Moins N. First in vivo SPECT imaging of mouse femorotibial cartilage using 99mTc-NTP 15-5. Mol Imaging 2008;7:263-71.

20. Kim SJ, Lee JS, Im KC, Kim SY, Park SA, Lee SJ, et al. Kinetic modeling of 3'-deoxy-3'-18F-fluorothymidine for quantitative cell proliferation imaging in subcutaneous tumor models in mice. $\mathrm{J}$ Nucl Med 2008;49:2057-66.

21. Wirrwar A, Buchholz D, Gottschalk O, Viehöver S, Schramm NU, Müller HW. Dynamic observation of the three-dimensional distribution of labeled liposomes using the novel high-resolution singlephoton emission computed tomography. Mol Imaging 2008;7:234-8.

22. Gabrielson KL, Mok GS, Nimmagadda S, Bedja D, Pin S, Tsao A, et al. Detection of dose response in chronic doxorubicin-mediated cell death with cardiac technetium $99 \mathrm{~m}$ annexin V single-photon emission computed tomography. Mol Imaging 2008;7:132-8.

23. Hume SP, Gunn RN, Jones T. Pharmacological constraints associated with positron emission tomographic scanning of small laboratory animals. Eur J Nucl Med 1998;25:173-6.

24. Hwang AB, Franc BL, Gullberg GT, Hasegawa BH. Assessment of the sources of error affecting the quantitative accuracy of SPECT imaging in small animals. Phys Med Biol 2008;53:2233-52.

25. Acton PD, Choi SR, Plössl K, Kung HF. Quantification of dopamine transporters in the mouse brain using ultra-high resolution single-photon emission tomography. Eur J Nucl Med Mol Imaging 2002;29:691-8.

26. Scherfler C, Scholz SW, Donnemiller E, Decristoforo C, Oberladstätter M, Stefanova N, et al. Evaluation of [123I]IBZM pinhole SPECT for 
the detection of striatal dopamine D2 receptor availability in rats. Neuroimage 2005;24:822-31.

27. Nikolaus S, Larisch R, Beu M, Antke C, Kley K, Forutan F, et al. Investigating the dopaminergic synapse in vivo. II. Molecular imaging studies in small laboratory animals. Rev Neurosci 2007; 18:473-504.

28. Jongen C, de Bruin K, Beekman F, Booij J. SPECT imaging of D2 dopamine receptors and endogenous dopamine release in mice. Eur J Nucl Med Mol Imaging 2008;35:1692-8.

29. Meyer-Kirchrath J, Martin M, Schooss C, Jacoby C, Flögel U, Marzoll A, et al. Overexpression of prostaglandin EP3 receptors activates calcineurin and promotes hypertrophy in murine heart. Cardiovasc Res 2009;81:310-8.

30. Pissarek M, Oros-Peusquens AM, Schramm NU. Challenge by the murine brain: multi-pinhole SPECT of 123I-labelled pharmaceuticals. J Neurosci Methods 2008;168:282-92.

31. Vollmar S, Hampl JA, Kracht L, Herholz K. Integration of functional data (PET) into brain surgery and neuronavigation. In: Buzug TM, editor. Advances in medical engineering, vol 114. Berlin: Springer; 2007. p. 98-103.

32. Lackas C, Hoppin J, Pissarek M, Schramm NU. Multi-pinhole SPECT with helical scanning. Mol Imaging 2005;4:364.

33. Fueger GF, Schreiner W. Dosimetrie offener Radionuklide. Vienna: Informatica Gesellschaft; 1985. p. 18-9.

34. Thie JA. Understanding the standardized uptake value, its methods, and implications of usage. J Nucl Med 2004;45:1431-4.

35. Langen KJ, Ziegler D, Weise F, Piolot R, Boy C, Hübinger A, et al. Evaluation of QT interval length, QT dispersion and myocardial m-iodobenzylguanidine uptake in insulin-dependent diabetic patients with and without autonomic neuropathy. Clin Sci (Lond) 1997;93:325-33.

36. Song S-M, Kim M-J, Lee J-M, Park H-J, Kim KM, Cheon G-J, et al. Coregistration of small animal PET and autoradiography for in vivoex vivo comparison. In: Rueda L, Mery D, Kittler J, editors. CIARP 2007, LNCS 4756, 2007. Berlin: Springer; 2007. p. 822-30.

37. Endres CJ, Bencherif B, Hilton J, Madar I, Frost JJ. Quantification of brain mu-opioid receptors with [11C]carfentanil: referencetissue methods. Nucl Med Biol 2003;30:177-86.

38. Thomas D, Bal H, Arkles J, Herowitz J, Araujo L, Acton PD, et al. Noninvasive assessment of myocardial viability in a small animal model: comparison of MRI, SPECT, and PET. Magn Reson Med 2008;59:252-9.

39. Vastenhouw B, van der Have F, van der Linden AJ, von Oerthel L, Booij J, Burbach JP, et al. Movies of dopamine transporter occupancy with ultra-high resolution focusing pinhole SPECT. Mol Psychiatry 2007;12:984-7.

40. Meyer PT, Salber D, Schiefer J, Cremer M, Schaefer WM, Kosinski $\mathrm{CM}$, et al. Cerebral kinetics of the dopamine $\mathrm{D}(2)$ receptor ligand [123I]IBZM in mice. Nucl Med Biol 2008;35:467-73.

41. Franc BL, Acton PD, Mari C, Hasegawa BH. Small-animal SPECT and SPECT/CT: important tools for preclinical investigation. J Nucl Med 2008;49:1651-63.

42. Andringa G, Drukach B, Bol JG, de Bruin K, Sorman K, Habraken JB, et al. Pinhole SPECT imaging of dopamine transporters correlates with dopamine transporter histochemical analysis in the MPTP mouse model of Parkinson's disease. Neuroimage 2005;26:1150-8.

43. Chalon S, Guimbal D, Guilloteau D, Mayo W, Huguet F, Schmitt $\mathrm{MH}$, et al. Iodobenzamide for in vivo exploration of central dopamine receptors: evaluation in animal models of supersensitivity. Life Sci 1990;47:729-34.

44. Singhaniyom W, Tsai YF, Brücke T, McLellan CA, Cohen RM, Kung HF, et al. Blockade of in vivo binding of 125I-labeled 3iodobenzamide (IBZM) to dopamine receptors by D2 antagonist and agonist. Brain Res 1988;453:393-6.
45. Wang X, Sarkar A, Cichetti F, Yu M, Zhu A, Jokivarsi K, et al. Cerebral PET imaging and histological evidence of transglutaminase inhibitor cystamine induced neuroprotection in transgenic R6/2 mouse model of Huntington's disease. J Neurol Sci 2005;231:57-66.

46. Alvarez-Fischer D, Blessmann G, Trosowski C, Béhé M, Schurrat T, Hartmann A, et al. Quantitative [123I]FP-CIT pinhole SPECT imaging predicts striatal dopamine levels, but not number of nigral neurons in different mouse models of Parkinson's disease. Neuroimage 2007;38:5-12.

47. Kung HF, Alavi A, Chang W, Kung MP, Keyes JW Jr, Velchik $\mathrm{MG}$, et al. In vivo SPECT imaging of CNS D-2 dopamine receptors: initial studies with iodine-123I-IBZM in humans. J Nucl Med 1990;31:573-9.

48. Kung MP, Kung HF. Mass effect of injected dose in small rodent imaging by SPECT and PET. Nucl Med Biol 2005;32:673-8.

49. Weber DA, Ivanovic M, Franceschi D, Strand SE, Erlandsson K, Franceschi M, et al. Pinhole SPECT: an approach to in vivo high resolution SPECT imaging in small laboratory animals. J Nucl Med 1994;35:342-8.

50. van Hemert FJ, Thurlings R, Dohmen SE, Voermans C, Tak PP, van Eck-Smit BL, et al. Labeling of autologous monocytes with $99 \mathrm{mTc}-\mathrm{HMPAO}$ at very high specific radioactivity. Nucl Med Biol 2007;34:933-8.

51. Westera G. SPECT: radiopharmaceuticals for perfusion imaging and tumor and inflammation localization in molecular anatomic imaging. In: von Schulthess GK, editor. Integrated modality imaging with PET-CT and SPECT-CT: CT issues. 2nd ed. Philadelphia: Lippincott Williams \& Wilkins; 2006. p. 128-32.

52. Danpure HI, Osman S. Investigations to determine the optimum conditions for radiolabelling human platelets with $99 \mathrm{mTc}-$ hexamethyl propylene amine oxime (99mTc-HM-PAO). Nucl Med Commun 1988;9:267-72.

53. Chiu ML, Kronauge JF, Piwnica-Worms D. Effect of mitochondrial and plasma membrane potentials on accumulation of hexakis (2-methoxyisobutylisonitrile) technetium(I) in cultured mouse fibroblasts. J Nucl Med 1990;31:1646-53.

54. Maisey MN, Mistry R, Sowton E. Planar imaging techniques used with technetium-99m sestamibi to evaluate chronic myocardial ischemia. Am J Cardiol 1990;66:47E-54E.

55. Yamaguchi H, Takeishi H, Ono S, Abe S, Tachibana H, Miyashita $\mathrm{T}$, et al. Myocardial $99 \mathrm{mTc}$ sestamibi washout in patients with dilated cardiomyopathy: comparisons with endomyocardial biopsy. Circ J 2003;67:519.

56. Machulla HJ, Knust EJ, Vyska K, Wolf M. Effects of propionic acid and 2-Br-palmitic acid on the uptake of fatty acids in heart tissue of mice. J Radioanal Nucl Chem 1989;136:247-56.

57. Zhou R, Thomas DH, Qiao H, Bal HS, Choi SR, Alavi A, et al. In vivo detection of stem cells grafted in infarcted rat myocardium. J Nucl Med 2005;46:816-22.

58. Beekman FJ, van der Have F, Vastenhouw B, van der Linden AJ, van Rijk PP, Burbach JPH, et al. U-SPECT-I: a novel system for submillimeter-resolution tomography with radiolabeled molecules in mice. J Nucl Med 2005;46:1194-200.

59. Idia H, Ebel S, Kim KM, Tamura Y, Ono Y, Nakazawa M, et al. Absolute quantitation of myocardial blood flow with (201) Tl and dynamic SPECT in canine: optimisation and validation of kinetic modelling. Eur J Nucl Med Mol Imaging 2008;35:896-905.

60. Da Silva AJ, Tang HR, Wong KH, Wu MC, Dae MW, Hasegawa $\mathrm{BH}$. Absolute quantification of regional myocardial uptake of 99mTc-sestamibi with SPECT: experimental validation in a porcine model. J Nucl Med 2001;42:772-9.

61. Funk T, Sun M, Hasegawa BH. Radiation dose estimate in small animal SPECT and PET. Med Phys 2004;31:2680-6.

62. Dormehl IC, Hugo N, Rossouw D, White A, Feinendegen LE. Planar myocardial imaging in the baboon model with iodine-123- 
15-(iodophenyl)pentadecanoic acid (IPPA) and iodine-123-15-(Piodophenyl)-3-R,S-methylpentadecanoic acid (BMIPP), using time-activity curves for evaluation of metabolism. Nucl Med Biol 1995;22:837-47.

63. Vandervoort E, Sossi V. Impact of contamination from scattered photons in singles-mode transmission data on quantitative small animal PET imaging. J Nucl Med 2008;49:1852-61.

64. Vunckx K, Suetens P, Nuyts J. Effect of overlapping projections on reconstruction image quality in multipinhole SPECT. IEEE Trans Med Imaging 2008;27:972-83.
65. Cao Z, Bal G, Accorsi R, Acton PD. Optimal number of pinholes in multi-pinhole SPECT for mouse brain imaging - a simulation study. Phys Med Biol 2005;50:4609-24.

66. DiFilippo FP. Geometric characterization of multi-axis multipinhole SPECT. Med Phys 2008;35:181-94.

67. Cherry SR. Multimodality in vivo imaging systems: twice the power or double the trouble? Annu Rev Biomed Eng 2006;8:35-62.

68. Funk T, Kirch DL, Koss JE, Botvinick E, Hsegawa BH. A novel approach to multipinhole SPECT for myocardial perfusion imaging. J Nucl Med 2006;47:595-602. 